\title{
Expression of Vesicular Glutamate Transporters Type 1 and 2 in Sensory and Autonomic Neurons Innervating the Mouse Colorectum
}

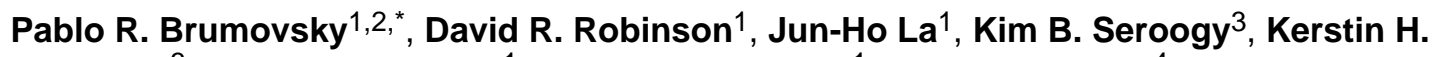 \\ Lundgren $^{3}$, Kathryn M. Albers ${ }^{1}$, Michael E. Kiyatkin ${ }^{1}$, Rebecca P. Seal ${ }^{4}$, Robert H. \\ Edwards $^{4}$, Masahiko Watanabe ${ }^{5}$, Tomas Hökfelt $^{6}$, and G.F. Gebhart ${ }^{1}$ \\ ${ }^{1}$ Pittsburgh Center for Pain Research, Department of Anesthesiology, University of Pittsburgh, \\ Pittsburgh, Pennsylvania 15213 \\ ${ }^{2}$ CONICET (Consejo Nacional de Investigaciones Científicas y Técnicas), Buenos Aires, \\ Argentina \\ ${ }^{3}$ Department of Neurology, University of Cincinnati, College of Medicine, Cincinnati, Ohio \\ 45267-0536 \\ ${ }^{4}$ Program in Neurosciences, University of California, School of Medicine, San Francisco, \\ California 94143 \\ ${ }^{5}$ Department of Anatomy, Hokkaido University School of Medicine, Sapporo 060-8638, Japan \\ ${ }^{6}$ Department of Neuroscience, Karolinska Institutet, Stockholm, SE 17177, Sweden
}

\begin{abstract}
Vesicular glutamate transporters (VGLUTs) have been extensively studied in various neuronal systems, but their expression in visceral sensory and autonomic neurons remains to be analyzed in detail. Here we studied VGLUTs type 1 and 2 (VGLUT 1 and VGLUT 2 , respectively) in neurons innervating the mouse colorectum. Lumbosacral and thoracolumbar dorsal root ganglion (DRG), lumbar sympathetic chain (LSC), and major pelvic ganglion (MPG) neurons innervating the colorectum of BALB/C mice were retrogradely traced with Fast Blue, dissected, and processed for immunohistochemistry. Tissue from additional naïve mice was included. Previously characterized antibodies against VGLUT $_{1}$, VGLUT $_{2}$, and calcitonin gene-related peptide (CGRP) were used. Riboprobe in situ hybridization, using probes against VGLUT VI $_{1}$ and VGUT 2 , was also performed. Most colorectal DRG neurons expressed VGLUT 2 and often colocalized with CGRP. A smaller percentage of neurons expressed VGLUT $_{1}$. VGLUT 2 -immunoreactive (IR) neurons in the MPG were rare. Abundant VGLUT 2 -IR nerves were detected in all layers of the colorectum; VGLUT $_{1^{-}}$ IR nerves were sparse. A subpopulation of myenteric plexus neurons expressed VGLUT2 protein and mRNA, but VGLUT1 mRNA was undetectable. In conclusion, we show 1) that most colorectal DRG neurons express VGLUT 2 , and to a lesser extent, VGLUT $_{1} ; 2$ ) abundance of VGLUT2-IR fibers innervating colorectum; and 3) a subpopulation of myenteric plexus neurons expressing $\mathrm{VGLUT}_{2}$. Altogether, our data suggests a role for $\mathrm{VGLUT}_{2}$ in colorectal glutamatergic neurotransmission, potentially influencing colorectal sensitivity and motility.
\end{abstract}

(C) 2011 Wiley-Liss, Inc.

"CORRESPONDENCE TO: Pablo R. Brumovsky, Faculty of Biomedical Sciences, Austral University, Av. Juan D. Perón 1500, B1629AHJ, Pilar, Buenos Aires, Argentina. brumovskypr@upmc.edu or pbrumovs@cas.austral.edu.ar.

Current address for Pablo R. Brumovsky: Faculty of Biomedical Sciences, Austral University, Av. Juan D. Perón 1500, B1629AHJ,

Pilar, Buenos Aires, Argentina.

Current address for David R. Robinson: Swanson School of Engineering, University of Pittsburgh, Pittsburgh, PA 15213. 


\section{INDEXING TERMS}

colon; DRG; glutamate; neuropeptides; pain; pelvic nerve

Glutamate, the principal excitatory neurotransmitter in neurons throughout the nervous system (Fonnum, 1984; Hökfelt et al., 1984; Watkins, 2000), is incorporated into synaptic vesicles by vesicular glutamate transporters (VGLUTs) (Liguz-Lecznar and SkangielKramska, 2007). To date, three subtypes (VGLUT $1, \mathrm{VGLUT}_{2}$, and $\mathrm{VGLUT}_{3}$ ) have been identified (Ni et al., 1994; Bellocchio et al., 2000; Aihara et al., 2000; Takamori et al., 2001; Fremeau et al., 2002).

Initially, glutamatergic neurons were morphologically studied under the optical or electron microscope by immunohistochemical detection of the neurotransmitter itself (StormMathisen et al., 1983; Ottersen, 1987; De Biasi and Rustioni, 1988). However, the presence of glutamate in a neuron does not directly imply its use as a neurotransmitter since the amino acid also serves as a precursor for the synthesis of other molecules, including GABA (Broman et al., 2000). Alternatively, detection of indirect markers such as glutaminase, the enzyme synthesizing glutamate (Kaneko et al., 1990), or glutamate transporters located in neuronal and glial plasma membranes (see Kanner and Schuldiner, 1987; Danbolt, 2001) has also been used. However, because of the high specificity of VGLUTs to a glutamatergic phenotype, the use of selective antibodies or in situ hybridization probes for their detection has become the gold standard for the identification of glutamatergic neurons (Fremeau et al., 2004; Moriyama and Yamamoto, 2004) and glutamate in glia (Montana et al., 2004; Anlauf and Derouiche, 2005).

The expression of VGLUT 1 and VGLUT 2 transcripts and proteins in dorsal root ganglion (DRG) sensory neurons innervating the skin has been studied in detail in the rat (Oliveira et al., 2003; Hwang et al., 2004; Landry et al., 2004; Morris et al., 2005), mouse, and guinea pig (Morris et al., 2005; Brumovsky et al., 2007). More recently, the presence of chimeric enhanced green fluorescent protein (EGFP) under control of the $\mathrm{VGLUT}_{3}$ promoter was shown in a subpopulation of L4-5 DRG neurons (Seal et al., 2009). In the rodent spinal cord all three transporters are present, although with different patterns of distribution, including dorsal vs. ventral or lateral horns, neuropil vs. cell body expression (Oliveira et al., 2003; Todd et al., 2003; Li et al., 2003a, b; Landry et al., 2004; Alvarez et al., 2004; Morris et al., 2005; Brumovsky et al., 2007; Seal et al., 2009). In contrast to nonvisceral neurons, the expression of VGLUTs in neurons innervating visceral organs has been studied mostly in relation to the upper gut.

The gut is a visceral structure subject to control by extrinsic and intrinsic innervations (see Robinson and Gebhart, 2008). The extrinsic innervation includes sensory nerves contributed by nodose and DRG neurons (Blackshaw et al., 2007) and autonomic (sympathetic and parasympathetic) nerves derived from neurons located in the lumbar sympathetic chain and prevertebral ganglia (Furness, 2006; Burnstock, 2009a). The presence of VGLUT $_{2}$ has been shown in nodose ganglia and DRG neurons innervating the stomach or ileum of rat (Tong et al., 2001; Corbett et al., 2005), as well as in specialized axonal terminations of vagal afferent fibers in esophageal myenteric ganglia (Berthoud et al., 1997) called intraganglionic laminar endings (IGLEs) in the rat, mouse (Raab and Neuhuber, 2003, 2004, 2005), and guinea pig (Zagorodnyuk et al., 2003). In addition, esophageal IGLEs in the guinea pig (Zagorodnyuk et al., 2003) and rat (Ewald et al., 2006), but not the mouse (Kraus et al., 2007), express VGLUT $_{1}$. A few studies in the lower gut show that VGLUTs are also present in axonal terminations in the guinea pig (Olsson et al., 2004) and mouse (Spencer et al., 2008) rectum. 
Sensory and motor neurons located in the myenteric and submucosal plexuses, and collectively referred to as enteric neurons, form the intrinsic innervation of the gut (Furness et al., 2004; Burnstock, 2009a). Enteric neurons containing glutamate have been described in rat and guinea pig ileum (Liu et al., 1997) as well as in rat stomach (Tsai et al., 1994) and VGLUT $_{1}$ and/or VGLUT 2 was reported present in enteric neurons in guinea pig, rat, mouse (Tong et al., 2001) and human ileum (Linke et al., 2008) and rat and mouse esophagus (Ewald et al., 2006; Kraus et al., 2007). However, in guinea pig colon evidence suggests that VGLUT $_{1}$ and VGLUT 2 are not expressed by myenteric plexus neurons (Olsson et al., 2004).

Despite extensive study of VGLUTs, a comprehensive account of their expression in rodent visceral sensory neurons innervating the distal gut has not been reported. Therefore, in the present study we analyzed the expression of VGLUT 1 and VGLUT $_{2}$ in mouse DRG, lumbar sympathetic chain, and major pelvic ganglion neurons retrogradely labeled from the colorectum using Fast Blue. Identification of VGLUT ${ }_{1}$ - and VGLUT $_{2}$-expressing colorectal neurons was made by immunohistochemistry using two well-characterized antibodies (Kawamura et al., 2006; Brumovsky et al., 2007). In addition, we explored the potential glutamatergic phenotype of colorectal myenteric plexus neurons by immunohistochemistry and riboprobe in situ hybridization. Finally, we studied coexpression of these transporters with CGRP in DRG and the colorectum. Portions of these data have been reported in abstract form (Gebhart et al., 2008).

\section{MATERIALS AND METHODS}

Male BALB/c (Taconic, Germantown, NJ; 7-8 weeks old) were used in all experiments. All research protocols adhered to the United States Public Health Service policies regarding the care and use of animals in research and were reviewed and approved by the Institutional Animal Care Use Committee of the University of Pittsburgh.

\section{Retrograde tracing}

The colon of six BALB/c male mice, 6 weeks old, was injected with the fluorescent retrograde neuronal tracer Fast Blue (FB, 2\% in saline; EMS-Chemie, Gross Umstadt, Germany) (Robinson et al., 2004). Under aseptic conditions, animals were anesthetized with isoflurane (Hospira, Lake Forest, IL) and injected with buprenorphine $(0.1 \mathrm{mg} / \mathrm{kg}$; Bedford Labs, Bedford, $\mathrm{OH}$ ) for postoperative analgesia. Following laparotomy, three to five injections $(\approx 5 \mu \mathrm{l}$, using a Hamilton syringe with a $25 \mathrm{G}$ needle) of FB were made at different sites into the wall of the descending colon. Care was taken not to allow the dye to spread to areas other than the injection site, both by containing any spillage using a cotton tip and by rinsing the peritoneal cavity with sterile saline before suturing muscle and skin. After treating the skin incision with dibucaine ointment (1\%; Perrigo, Allegan, MI), mice were allowed to recover in a warm environment under close observation.

\section{Immunohistochemistry}

Tissue preparation-Twelve days after injection of $\mathrm{FB}$, and including seven naïve $\mathrm{BALB} / \mathrm{C}$ mice, the animals were deeply anesthetized using sodium pentobarbital $(60 \mathrm{mg} / \mathrm{kg}$, intraperitoneally [i.p.]; Ovation Pharmaceuticals, Deerfield, IL) and perfused via the ascending aorta with $20 \mathrm{ml}$ of Tyrode's buffer $\left(37^{\circ} \mathrm{C}\right)$, followed by $20 \mathrm{ml}$ of a mixture of $4 \%$ paraformaldehyde and $0.2 \%$ picric acid dissolved in $0.16 \mathrm{M}$ phosphate buffer $(\mathrm{pH} 6.9)$ $\left(37^{\circ} \mathrm{C}\right)$ and $50 \mathrm{ml}$ of the same mixture at $4^{\circ} \mathrm{C}$, the latter for $\approx 5-7$ minutes. Thoracolumbar (T8-L1; TL) and lumbosacral (L6-S2; LS) DRGs, the major pelvic ganglion (MPG), the lumbar sympathetic chain (LSC), and the colorectum were dissected out and postfixed for 90 minutes at $4{ }^{\circ} \mathrm{C}$ in the same fixative and immersed in 10-20\% sucrose in phosphatebuffered saline (PBS) (pH 7.4) containing $0.01 \%$ sodium azide and $0.02 \%$ bacitracin (both 
from Sigma, St. Louis, MO) $\left(4^{\circ} \mathrm{C}\right)$ for 48 hours. After embedding in Tissue-Tek O.C.T. compound (Sakura, Torrance, CA) and deep freezing on dry ice, tissue was sectioned in a

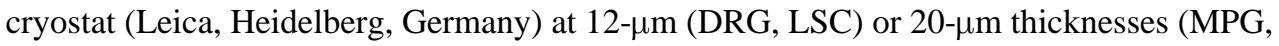
colon).

Antibody characterization-Table 1 lists the antibodies used in this study. The VGLUT $_{1}$ and VGLUT $_{2}$ antibodies were raised against the C-terminal sequence of rat VGLUT $_{1}$ (531-560 amino acid residues, GenBank accession number U07609; Miyazaki et al., 2003) or rat VGLUT 2 (519-582 amino acid residues, GenBank accession number AF271235; Miyazaki et al., 2003). Antibodies against C-terminus polypeptide-glutathione-S transferase (GST) fusion proteins were raised and affinity purified by affinity media coupled with GST-free polypeptides (Miyazaki et al., 2003; Kawamura et al., 2006; Miura et al., 2006). Antibody specificity was tested by immunoblot of mouse brain extracts, with detection of a single band at $60 \mathrm{kDa}$ for both $\mathrm{VGLUT}_{1}$ and $\mathrm{VGLUT}_{2}$ (Miyazaki et al., 2003; Kawamura et al., 2006; Miura et al., 2006), and also by immunostaining patterns in the adult mouse brain, which were identical to previous reports by immunohistochemistry and in situ hybridization. Specifically for DRGs, the VGLUT $_{1}$ and VGLUT $_{2}$ antibodies produced immunohistochemical patterns identical to those previously described in an earlier publication (Brumovsky et al., 2007). In addition, combined in situ hybridizationimmunohistochemistry studies show colocalization of transcript and protein of these two VGLUTs in the same DRG neurons (see Results).

Finally, the rabbit polyclonal antibody raised against the rat CGRP (Sigma) is a delipidized whole antiserum that recognizes CGRP in both rats and mice (due to the conserved sequence of CGRP between the two rodents). In dotblot experiments there is negligible crossimmunoreactivity with calcitonin, somatostatin, and amylin (Zhang et al., 2001). Moreover, the CGRP immune signal is completely abolished in DRGs and the dorsal horn of the spinal cord of mice lacking CGRP (Zhang et al., 2001).

\section{Incubation protocol}

Single-staining (TSA plus): VGLUT 1 or VGLUT $\mathbf{2}_{\mathbf{2}}:$ Sections were washed twice in PBS and incubated for 24 hours at $4{ }^{\circ} \mathrm{C}$ with rabbit anti-VGLUT 1 (1:4,000; \#VGluT1-Rb-Af500; Frontier Science, Hokkaido, Japan) (Kawamura et al., 2006) or guinea pig anti-VGLUT 2 (1:8,000; \#VGluT2-GP-Af670-1; Frontier Science) (Miyazaki et al., 2003; Brumovsky et al., 2007 ) antibodies, diluted in 0.01 M PBS containing $0.3 \%$ Triton $\mathrm{X}-100$ and $0.5 \%$ bovine serum albumin (BSA).

To visualize immunoreactivity, sections were processed using a commercial kit based on tyramide signal amplification (Adams, 1992) (TSA Plus, NEN Life Science Products, Boston, MA). Briefly, the sections were washed in TNT buffer (0.1 M Tris-HCl, $\mathrm{pH} 7.5$; $0.15 \mathrm{M} \mathrm{NaCl} ; 0.05 \%$ Tween 20) for 10 minutes, incubated with TNB buffer kit (0.1 M Tris$\mathrm{HCl}, \mathrm{pH} 7.5 ; 0.15 \mathrm{M} \mathrm{NaCl} ; 0.5 \%$ Dupont Blocking Reagent; NEN) for 30 minutes at room temperature (RT) and incubated for 60 minutes with either a donkey antirabbit or antiguinea pig/horseradish peroxidase (HRP) conjugate (Jackson ImmunoResearch, West Grove, PA) diluted 1:200 in TNB buffer. The sections were washed twice in TNT buffer and incubated in a biotinyl tyramide-fluoride thiocyanate (BT-FITC) conjugate kit (NEN) diluted 1:700 in amplification diluent kit (NEN) for 30 minutes at RT.

Double-staining (TSA plus combined with indirect immunofluorescence): VGLUT 1 or VGLUT 2 plus CGRP: After incubation with VGLUT $_{1}$ or VGLUT 2 , antiserum, and followed by the TSA plus technique for visualization of each primary antibody (as above), some sections were washed in PBS, incubated with a rabbit anti-CGRP antibody $(1: 8,000$; 
\#C8198; Sigma), and processed according to Coons (1958). Sections were incubated for 24 hours at $4^{\circ} \mathrm{C}$ with the anti-CGRP antiserum, washed twice in PBS, and further incubated using a tetramethyl rhodamine isothiocyanate (TRITC)-conjugated donkey antirabbit antibody (1:400; Jackson ImmunoResearch).

Controls-To test for nonspecific staining by the secondary antibody, the primary antibody was omitted from a few control sections. Also, single-stained sections were processed for comparison with double-stained sections. The rabbit VGLUT ${ }_{1}$ antiserum was studied after preadsorption with the C-terminal 531-560 amino acid peptide $\left(10^{-5}\right.$ and $10^{-6} \mathrm{M}$ ), which gave no visible fluorescent signal (data not shown). CGRP and VGLUT 2 antisera have been thoroughly characterized in previous publications (Robinson et al., 2004; Brumovsky et al., 2007). Specificity of the VGLUT antibodies was further assessed through combined in situ hybridization-immunohistochemistry studies (see below).

\section{Whole mount preparation}

Four male BALB/c mice, 7-8 weeks old, were transcardially perfused with fixative as above and their colorectum removed. Immediately after, and under a dissecting microscope, the colorectum was opened along the longitudinal axis, pinned flat, and denuded of the mucosal, submucosal, and circular muscle layers using fine dissection forceps. The remaining tissue (longitudinal muscle layer and myenteric plexus) was incubated in the same fixative for 90 minutes and transferred into wells containing PBS, after which free-floating immunohistochemistry was initiated.

\section{Single-staining (TSA plus)}

VGLUT $_{1}$ or VGLUT : $_{2}$ :Whole-mount preparations were placed in 24-well cell culture chambers (Corning, Corning, NY), rinsed three times in PBS (15 minutes each), and incubated for 24 or 48 hours at $4^{\circ} \mathrm{C}$ with rabbit anti-VGLUT $1(1: 4,000)$ or guinea pig anti$\operatorname{VGLUT}_{2}(1: 8,000)$ antiserum diluted in $0.01 \mathrm{M}$ PBS containing $0.3 \%$ Triton X-100 and $0.5 \%$ BSA. For all solutions $300-500 \mu \mathrm{l}$ per well was used. To visualize immunoreactivity, tissue was processed using a modified TSA protocol. Briefly, the whole mounts were washed twice in TNT buffer for 15 minutes, incubated with TNB buffer for 1 hour at RT, and then incubated for 24 hours at $4{ }^{\circ} \mathrm{C}$ with a donkey antirabbit or antiguinea pig/HRP conjugate (Jackson ImmunoResearch) diluted 1:400 in TNB buffer. The preparations were washed twice in TNT buffer (15 minutes each) and incubated in a BT-FITC conjugate diluted 1:1,000 in amplification diluent for 2 hours at RT, then washed twice in TNT (15 minutes each) and twice in PBS. Some whole mounts were additionally incubated with propidium iodide (PI; Sigma) diluted at $0.0001 \%$ in TNT, followed by three washes in TNT buffer.

\section{Riboprobe in situ hybridization}

Male, 7-week-old, BALB/c mice $(n=4)$ were used for in situ hybridization analysis. Mice were briefly sedated using $\mathrm{CO}_{2}$ before rapid decapitation. The colorectum, brainstem, and L4-5 DRGs were quickly removed, embedded in O.C.T. (Tissue-Tek), and frozen over dry ice. Sections of colorectum and brainstem $(20 \mu \mathrm{m})$ were cut in a cryostat, thaw-mounted onto Superfrost Plus (Fisher Scientific, Waltham, MA) glass slides, and stored at $-20^{\circ} \mathrm{C}$ until hybridization. Adjacent sections through the different tissues were processed for in situ hybridization localization of VGLUT 1 and $\mathrm{VGLUT}_{2}$ mRNAs using ${ }^{35} \mathrm{~S}$-labeled cRNA probes as described previously (Seroogy and Herman, 1997; Numan et al., 2005; Dickerson et al., 2009). Briefly, the slide-mounted sections were brought to RT and then placed in $4 \%$ paraformaldehyde for 10 minutes. This was followed by washes in $0.1 \mathrm{M}$ phosphate buffer $(\mathrm{PB}), 0.1 \mathrm{M} \mathrm{PB} / 0.2 \%$ glycine, and $0.25 \%$ acetic anhydride in $0.1 \mathrm{M}$ triethanolamine. The 
sections were then dehydrated with increasing concentrations of ethanol, delipidated in chloroform, and air-dried. Sections were hybridized for $18-24$ hours at $60^{\circ} \mathrm{C}$ in hybridization cocktail $(0.15 \mathrm{mg} / \mathrm{ml}$ yeast tRNA, $10 \%$ dextran sulfate, $50 \%$ formamide, $1 \times$ Denhardt's solution, $1 \mathrm{mM}$ EDTA, $20 \mathrm{mM}$ Tris- $\mathrm{HCl}, 40 \mathrm{mM}$ dithiothreitol, $0.33 \mathrm{mg} / \mathrm{ml}$ denatured salmon sperm DNA) and the ${ }^{35} \mathrm{~S}$-labeled cRNA probe at a concentration of $1.0 \times$ $10^{6} \mathrm{cpm} / 50 \mu \mathrm{l}$ per slide.

Sense and antisense probes complementary to the coding region of mouse VGLUT $_{1}$ (nucleotides 855-1788; GenBank accession number XM_133432.2) and VGLUT 2 (nucleotides 848-2044; GenBank accession number NM_080853.2) were generously provided by Dr. Akiya Watakabe, National Institute for Basic Biology, Okazaki, Japan (Nakamura et al., 2007). The sense and antisense cRNA probes were prepared by in vitro transcription using appropriate linearized DNA constructs in the presence of the corresponding RNA polymerase (T3 or T7) and ${ }^{35}$ S-UTP (New England Nuclear, Perkin Elmer, Waltham, MA). For posthybridization treatment, sections were washed several times in $4 \times \mathrm{SSC}(1 \times \mathrm{SSC}=0.015 \mathrm{M}$ sodium citrate, $0.15 \mathrm{M}$ sodium chloride at $\mathrm{pH} 7.0)$ containing $10 \mathrm{mM}$ sodium thiosulfate at $37^{\circ} \mathrm{C}$. The sections were then incubated in ribonuclease A $(0.05 \mathrm{mg} / \mathrm{mL})$ for 30 minutes at $45^{\circ} \mathrm{C}$. This was followed by several washes in decreasing concentrations of SSC $(2 \times, 0.5 \times$, and $0.1 \times)$ at $37^{\circ} \mathrm{C}$. All but the final wash also contained 10 $\mathrm{mM}$ sodium thio-sulfate. The sections were briefly rinsed in distilled water $\left(\mathrm{dH}_{2} \mathrm{O}\right)$, dipped in $95 \%$ ethanol, and finally air-dried.

Sections were dipped in NTB2 nuclear track emulsion (Kodak, Rochester, NY; 1:1 in $\mathrm{dH}_{2} \mathrm{O}$ ), air-dried, and exposed in sealed slide boxes at $4{ }^{\circ} \mathrm{C}$ for 3-7 days and 6-12 weeks, for DRGs and colon, respectively. The emulsion was developed in D19 (Kodak) and fixed with Rapidfix (Kodak). The slides were counterstained with cresyl violet (Sigma) and coverslipped with DPX mounting solution (Fluka, Buchs, Switzerland). As controls for specificity, some sections were pretreated with ribonuclease A $(0.05 \mathrm{mg} / \mathrm{ml})$ for 30 minutes at $45^{\circ} \mathrm{C}$ before hybridization with the ${ }^{35} \mathrm{~S}$-labeled cRNA probes. Some sections were also hybridized with sense-strand ${ }^{35} \mathrm{~S}$-labeled riboprobes against each VGLUT. Finally, several tissue sections were incubated in hybridization cocktail that lacked the radioactive probe as a chemography control. No specific labeling was observed under any of these conditions.

\section{Combined riboprobe in situ hybridization-immunohistochemistry experiments}

In order to establish if protein and transcript for VGLUT 1 and VGLUT 2 do coexist in the same DRG neurons, and to define the reliability of the antibodies and riboprobes utilized in the present study, we carried out combined ribop-robe in situ hybridizationimmunohistochemistry experiments (Seroogy et al., 1994; Seroogy and Herman, 1997). Briefly, naïve male 7-week-old BALB/c mice $(n=2)$ were deeply anesthetized, perfused, and the L4-5 DRGs quickly removed and treated as described above for immunohistochemistry. Tissue sections were cut in a cryostat, thaw-mounted onto Superfrost Plus glass slides, and processed for in situ hybridization localization of VGLUT $_{1}$ and VGLUT ${ }_{2}$ mRNAs using the appropriate riboprobes (see above). Following hybridization and posthybridization rinses in descending concentrations of SSC buffer, slides were rinsed with sterile $\mathrm{PB}$ and incubated overnight at $4{ }^{\circ} \mathrm{C}$ with $\mathrm{VGLUT}_{1}$ or VGLUT $_{2}$ antibodies (see Table 1) at a concentration of 1:3,000 and 1:6,000, respectively. This was followed by immunohistochemical processing using the avidin-biotin technique (Vectastain kit; Vector Laboratories, Burlingame, CA) and with diaminobenzidine as the chromagen. Slides were then rinsed in $50 \mathrm{mM}$ Tris, dehydrated in a series of ethanol at increasing concentrations, finishing in Xylene, and air-dried. After 24 hours slides were dipped in Kodak NTB autoradiography emulsion as described above. 


\section{Microscopy and image processing}

All sections and whole-mount preparations were cover-slipped using 2.5\% DABCO in glycerol (Sigma) and examined with a Nikon Eclipse E600 fluorescence microscope (Nikon, Tokyo, Japan) with appropriate filters and a Retiga 2000 R Fast CCD camera (Q-Imaging, Surrey, British Columbia, Canada) using IPLab software (Scanalytics, Vancouver, Canada). For colocalization analysis of the colon, MPG, and the LSC, a Fluoview FV 1000 confocal laser scanning biological microscope equipped with $10 \times(0.45$ N.A. $), 20 \times(0.75$ N.A. $)$, and $60 \times$ oil (1.40 N.A.) objectives was used (Olympus, Tokyo, Japan). The FITC labeling was excited using a 547-514 $\mathrm{nm}$ argon multiline laser. For the detection of TRITC and TMR, a $543 \mathrm{~nm}$ HeNe laser was used.

Resolution, brightness, and contrast of the images were optimized using the Adobe Photoshop CS3 software (Adobe Systems, San Jose, CA). Because confocal imaging of FB was not possible due to lack of appropriate filters, images were composed by merging separate optical (FB) and confocal (other markers of interest) photomicrographs.

\section{Quantification}

Retrogradely traced colorectal neurons were quantified in T8-T13 and L6-S2 DRGs. Every fifth DRG section was used to quantify the number of FB-positive (colonic) neuron profiles (NPs), as well as the number of colonic VGLUT $1^{-}$, and VGLUT $_{2}$-immunoreactive (IR) NPs present in each section. In total, 5-8 sections per ganglion were used for quantification. The cell body diameters of a representative sample of each type of quantified neurons (more than 20 and up to 69 neurons per type) were measured using the public domain NIH program ImageJ (developed at the U.S. National Institutes of Health and available on the Internet at http://rsb.info.nih.gov/ij/download.html), and these data used to correct the raw counts, based on the Abercrombie correction factor (Abercrombie, 1946; Guillery, 2002). Percentages of VGLUT-expressing colorectal neurons were obtained by counting, within the total number of FB-positive colorectal neurons, those expressing or not $\mathrm{VGLUT}_{1}$ or $\operatorname{VGLUT}_{2}$.

Due to the very low background obtained with the TSA plus technique, we were able to detect a variety of immunofluorescent signal intensities for both VGLUT $_{1}$ and VGLUT 2 , ranging from intensely to lightly stained NPs. Moreover, negative neurons were seen as virtually completely black, and thus most neurons showing VGLUT-signal were easily identified. However, to avoid occasional false-positives we counted those NPs exhibiting an intensity of immunostaining higher than two orders of magnitude, and when intracellular structures such as the Golgi apparatus or the endoplasmic reticulum could be observed. In the case of the combined riboprobe in situ hybridization-immunohistochemistry, it should be noted that the immunohistochemical VGLUT 1 and VGLUT $_{2}$ signals obtained when using the avidinbiotin/diaminobenzidine technique produced a background staining that appeared to also be influenced by the antibody used. In the present study we discriminated between VGLUT $_{1}, \mathrm{VGLUT}_{2}$, and background by only including those NPs that showed a signal that was at least three orders of magnitude above the negative signal obtained from, for example, the nerve bundles in the DRGs (not shown). Riboprobe in situ hybridization signals were analyzed in such a way that only neurons where the density of accumulation of silver grains over a single NP was more than 5 times that of background were counted as labeled.

\section{Statistics}

Data are presented as mean \pm SEM and were statistically analyzed using Student's $t$-test for independent samples; $P<0.05$ was considered significant. 


\section{RESULTS}

\section{Methodological considerations concerning the expression of VGLUTs in colorectal DRG neurons}

In the present study we studied the expression of VGLUT 1 and $\mathrm{VGLUT}_{2}$ in colorectal DRG neurons and neurons in the myenteric plexus, following two different approaches: 1) by immunohistochemical detection of VGLUT 1 and VGLUT 2 using two previously characterized antibodies (Table 1; DRG and myenteric neurons); and 2) by evaluating the coexpression of VGLUTs transcript and protein by means of combined riboprobe in situ hybridization-immunohistochemistry, utilizing previously characterized VGLUT riboprobes (Nakamura et al., 2007).

Both the VGLUT 1 and VGLUT 2 antibodies produced distinct immunohistochemical signals (Fig. 1A,B, respectively) that also matched previously described patterns of immunoreactivity (see below and Morris et al., 2005; Brumovsky et al., 2007). However, to certify the specificity of the probes we carried out combined riboprobe in situ hybridizationimmunohistochemistry studies and found that both $\operatorname{VGLUT}_{1}$ (Fig. 1C) or $\mathrm{VGLUT}_{2}$ (Fig. 1D) transcript and protein in fact coexpress, as shown by the colocalization of their respective in situ hybridization-immunohistochemical signals.

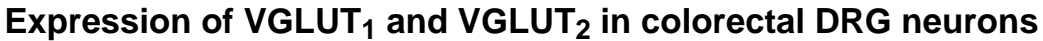

The rodent colorectum is innervated by lumbar splanchnic (LSN) and pelvic (PN) nerves with cell bodies located in T8-L1 and L6-S2 DRGs, respectively (Robinson and Gebhart, $2008)$. In the mouse, colorectal DRG neurons can be divided into small $\left(\approx 300 \mu \mathrm{m}^{2}\right)$, medium (350-600 $\mathrm{m}^{2}$ ), and large $\left(650->1,100 \mu \mathrm{m}^{2}\right)$ (Robinson et al., 2004; Tan et al., 2008). Retrograde tracing from the colorectum revealed a discrete number of FB-positive NPs of different sizes per section in these DRGs that were easily differentiated from FBnegative NPs (Figs. 2, 4).

Both VGLUT 1 and VGLUT 2 were expressed in mouse DRG neurons projecting to the colorectum (Table 2; Fig. 2). VGLUT 1 was present in $15 \pm 1.8 \%$ of TL and $8 \pm 1.1 \%$ of LS colorectal DRG NPs (Table 2; Fig. 2A-C), the majority of which appeared to be medium- to large-sized (Fig. 2A-C). VGLUT 2 , by far the most abundant VGLUT in DRG neurons, was detected in similar high proportions in TL $(98 \pm 1.2 \%)$ and LS $(97 \pm 1.4 \%)$ NPs of different sizes (Table 2; Fig. 2D-F). Colorectal DRG neurons lacking VGLUT 2 were also found (Fig. $2 \mathrm{G}-\mathrm{I})$. In contrast, $\mathrm{VGLUT}_{1}$ was present in a significantly greater percentage of TL colorectal DRG NPs compared with its LS counterpart (Table 2; $P=0.014$ ). Finally, in addition to colorectal neurons, abundant VGLUT $_{2}$ - and a considerable number of VGLUT $_{1^{-}}$ IR, FB-negative neurons were detected in all DRGs (Figs. 2, 4).

Colocalization analysis showed that $79.6 \pm 2.1 \%$ of TL and $83.6 \pm 2.3 \%$ of LS colorectal DRG NPs coexpressed VGLUT 2 and CGRP (Figs. 3, 4A-D). Many FB-negative VGLUT $2^{-}$ IR NPs coexpressing CGRP were also detected (Fig. 4A-D). In contrast to VGLUT 2 , virtually no VGLUT ${ }_{1}$ colorectal DRG NPs coexpressed CGRP in any of the studied DRGs (Fig. 4E-H). Moreover, FB-negative VGLUT 1 -IR NPs also lacked CGRP (Fig. 4E-H). CGRP-only colorectal DRG neurons were also seen (Fig. 4E-H).

\section{VGLUT expression in colorectal LSC and MPG neurons}

In the lumbar sympathetic chain (LSC), several neurons were retrogradely labeled from the colorectum by FB (Fig. 5B, E). None of these neurons showed the presence of VGLUT 1 or VGLUT $_{2}$ (Fig. 5A-C, 5D-F, respectively). However, a number of VGLUT 2 -IR fibers, as well as what seemed to be synaptic varicosities (Fig. 5D-F), were detected in LSCs. 
In the MPG, many neurons were retrogradely labeled from the colorectum by FB (Fig. 5H, K, N, Q). None of these neurons exhibited VGLUT 1 -like immunoreactivity (LI) (Fig. 5G-I), and the latter was only detected in a few varicose profiles (Fig. 5G). VGLUT 2 -IR colorectal MPG neurons were rarely found (Fig. 5J-L). As observed in the LSC, many VGLUT 2 -IR fibers and varicosities were detected in the MPG (Fig. 5J, L, M, O, P, R). Moreover, some of these varicosities appeared to be arranged in baskets surrounding colorectal (Fig. 5J-L, 5M$\mathrm{O})$ as well as noncolorectal MPG (Fig. 5P-R) neurons.

\section{VGLUT expression in the colorectum}

VGLUT $_{1}$-LI was restricted to a few nerve fibers found in the submucosal (Fig. 6A, B) and mucosal layers (Fig. 6C) of the colorectum. In contrast, a profuse VGLUT 2 -IR innervation was detected throughout (Fig. 6D), including the myenteric plexus (Figs. 6D, E) and submucosal and mucosal layers (Fig. 6D, F), even reaching the luminal aspects of the latter (Fig. 6F). Additional, nonspecific immunofluorescent cells were observed, usually in the mucosal layers (Fig. 6D, F). These cells were also seen after omission of the primary antibody (data not shown), strongly suggesting nonspecific binding of the secondary antibody.

VGLUT $_{1}$-LI was not detected (24-hour, free-floating immunohistochemistry) in wholemount preparations of the longitudinal muscle layer and myenteric plexus neurons and their projections (Fig. 7A). In contrast, a profuse $\mathrm{VGLUT}_{2}$-IR fiber network (Fig. 7B) was detected, often connecting different myenteric plexus ganglia (Fig. 7B) and forming numerous varicosities surrounding unstained myenteric plexus neurons (Fig. 7C). Prolonged free-floating immunohistochemistry of whole-mount preparations (48-hour) revealed the presence of a small population of VGLUT $_{2}$-IR myenteric plexus neurons (Fig. 7D-F). These neurons were sparsely distributed among the many myenteric ganglia present in the wholemount preparation, and neighboring other unstained myenteric plexus neurons (Fig. 7D-F).

In accordance with immunohistochemical results, in situ hybridization for detection of VGLUT mRNAs in the colorectum revealed the presence of VGLUT $_{2}$ mRNA in a subpopulation of myenteric plexus neurons (Fig. 8A-D). VGLUT 2 mRNA-positive neurons were present only at this location and absent in the submucosal plexus or elsewhere (Fig. 8A). In situ hybridization of sections tangential to the surface of the colorectum confirmed these observations. Thus, only a fraction of all neurons throughout the whole myenteric plexus were VGLUT 2 mRNA-positive (Fig. 8B-D). In fact, not all myenteric ganglia contained VGLUT 2 mRNA-positive neurons, and often only two or three neurons per ganglia expressed this VGLUT (Fig. 8C, D). Several VGLUT 2 mRNA-positive NPs were detected in L4-5 DRGs (Fig. 8E) using the antisense riboprobe, and the signal was absent with the sense riboprobe in both DRGs (Fig. 8F) and colorectum (Fig. 8G). The lack of signal seen with the sense probe certifies the specificity of the in situ hybridization signal. In contrast, no VGLUT 1 -mRNA expression (Fig. 8H-K) was detected in any of the colorectal layers. The same antisense riboprobes exposed a population of DRG neurons expressing VGLUT $_{1}$ (Fig. 8L); this signal was absent when incubating sections with the corresponding sense probe (Fig. 8M).

Colocalization analysis in the colorectum revealed that $\mathrm{VGLUT}_{2}$ highly coexpresses with CGRP in fibers present in the mucosal layer of the organ (Fig. 9A-C). In contrast, at the level of the myenteric plexus, VGLUT 2 and CGRP appeared to be present in independent fiber populations (Fig. 9D-I). 


\section{DISCUSSION}

In this study we characterized the glutamatergic innervation of the mouse colorectum using immunohistochemistry and in situ hybridization for the detection of VGLUT 1 and VGLUT 2 . Our results reveal that VGLUT 2 is the principal VGLUT in both the extrinsic and intrinsic innervations of the mouse colorectum, with a much lower percentage of colorectal DRG neurons expressing VGLUT 1 . Therefore, most extrinsic colorectal neurons in TL and LS DRGs appear to be glutamatergic. Significantly, the majority of these VGLUT $_{2}$-expressing neurons are also peptidergic, suggesting the possibility of neurotransmitter interactions upon release from synaptic terminals. $\mathrm{VGLUT}_{2}$-expressing nerve fibers are present in all layers of the colorectal wall, including the myenteric plexus and the mucosa. Further analysis of the myenteric plexus revealed a discrete population of enteric neurons expressing VGLUT $_{2}$ transcript and protein, suggesting local synthesis. In contrast, no VGLUT ${ }_{1}$-positive neurons were detected in the myenteric plexus. The presence of rare MPG neurons expressing VGLUT $_{2}$ suggests an additional autonomic source of glutamatergic innervation of the colorectum.

\section{Glutamatergic nature of colorectal DRG neurons}

Previous studies support the presence of VGLUTs in afferent sensory nerve terminals in the gut of the guinea pig, rat, and mouse (Raab and Neuhuber, 2003, 2004, 2005; Zagorodnyuk et al., 2003; Olsson et al., 2004; Ewald et al., 2006; Spencer et al., 2008). However, the proportion and phenotype of VGLUT-expressing vagal or DRG neurons giving rise to these endings has received limited attention. In the rat, Tong et al. (2001) and Corbett et al. (2005) reported expression of $\mathrm{VGLUT}_{2}$ (not quantified) in ganglia innervating the stomach (Tong et al., 2001; Corbett et al., 2005) or ileum (Tong et al., 2001). In addition, expression of VGLUT $_{2}$ and VGLUT $_{3}$ protein in rat nodose ganglion neurons supplying the aortic depressor nerve has also been described (Lin and Talman, 2006).

In the present study we show that more than $95 \%$ of mouse colorectal DRG neurons express VGLUT $_{2}$. These neurons varied in size, in agreement with previous studies showing that colonic neurons in the mouse (Robinson et al., 2004; Sugiura et al., 2007; Robinson and Gebhart, 2008) and rat (Keast and De Groat, 1992; Traub et al., 1999) are of small-tomedium size, including some with larger profiles. The abundant expression of $\mathrm{VGLUT}_{2}$, which not only encompassed colorectal, but also nontraced DRG neurons, correlates well with our earlier study in mouse ((Brumovsky et al., 2007), where we observed that up to $65 \%$ of the total number of L4-5 (nonvisceral) DRG neurons express VGLUT $_{2}$ (see Brumovsky et al., 2007). However, even though the hind-paw skin was the most likely destination, we did not trace this or other potential target tissues for the VGLUT $_{2}$-expressing DRG neurons (Brumovsky et al., 2007). That most if not all colorectal neurons in the mouse express VGLUT 2 , compared to the $65 \%$ expression reported in nonvisceral neurons (Brumovsky et al., 2007), suggests differences in the glutamatergic nature of neurons at different DRG levels, as well as target organs. Accordingly, Tong et al. (2001) reported that the majority of rat thoracic DRG neurons express $\mathrm{VGLUT}_{2}$, and that a subpopulation of these neurons innervates the ileum. In contrast to the abundance of VGLUT $2, V V_{L U T}$ was detected in less than $20 \%$ of colorectal DRGs. These observations are in agreement with the more discrete expression of VGLUT 1 in nonvisceral mouse DRG neurons (Morris et al., 2005; Brumovsky et al., 2007).

In the rat (Christianson et al., 2006; Robinson and Gebhart, 2008) and mouse (Robinson et al., 2004; Christianson et al., 2006; Robinson and Gebhart, 2008), the afferent innervation of the colorectum is provided by TL and LS DRG neurons. Interestingly, differences in the degree of expression of some neurochemical markers exist between mouse colorectal TL and LS DRG neurons (Brierley et al., 2005a; Christianson et al., 2006; Robinson and 
Gebhart, 2008). In support, we found that whereas the proportions of VGLUT 2 -expressing colorectal TL and LS DRG neurons are comparable, VGLUT 1 is generally lower at LS levels. Even though further research is required to understand the significance of these differences, they may relate to recently reported electrophysiological differences in the properties of TL and LS colorectal afferent neurons (Brierley et al., 2004, 2005a, b).

Through coexpression analysis with CGRP, we found that around $80 \%$ of all VGLUT 2 -IR colorectal DRG neurons are peptidergic, in clear contrast to the virtual absence of the peptide in colorectal neurons expressing $\mathrm{VGLUT}_{1}$. It has long been appreciated that CGRP is contained in rat visceral sensory neurons (Keast and De Groat, 1992; Bennett et al., 1996; Wang et al., 1998), findings that have been confirmed by recent work in rat (Christianson et al., 2006) and mouse (Robinson et al., 2004; Christianson et al., 2006). Overall, most studies report that 50-80\% of all colorectal DRG neurons express CGRP (Robinson and Gebhart, 2008), supporting our past (Brumovsky et al., 2007) and present observations of the peptidergic nature of $\mathrm{VGLUT}_{2}$-expressing neurons. Nonpeptidergic colorectal $\mathrm{VGLUT}_{2}$ -

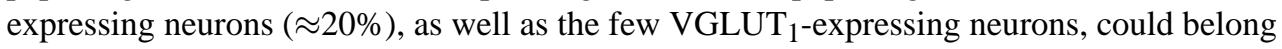
to the population of $\mathrm{IB}_{4}^{+}$DRG neurons (see Bennett et al., 1996; McMahon and Priestley, 2005). However, at least in nonvisceral mouse DRG neurons, VGLUT 1 and $\mathrm{IB}_{4}$ are never coexpressed (Morris et al., 2005; Brumovsky et al., 2007). Further study is necessary to elucidate the full phenotype of these neurons.

Initial observations in the adult mammalian brain established that VGLUTs exhibit a complementary distribution (Fremeau et al., 2001; Schäfer et al., 2002; Kaneko and Fujiyama, 2002; Boulland et al., 2004). However, recent studies suggest that some neurons in the central (Boulland et al., 2004) and peripheral (Li et al., 2003; Landry et al., 2004; Brumovsky et al., 2007) nervous systems express more than one type of VGLUT. In the present work the overwhelming presence of VGLUT 2 in virtually all colorectal DRG neurons suggests that some may also express VGLUT $_{1}$. We previously described a moderate VGLUT $_{1}$ and VGLUT 2 coexpression in nonvisceral DRG neurons (Brumovsky et al., 2007). Moreover, colocalization between these two VGLUTs has been shown in rat (Ewald et al., 2006) and mouse (Kraus et al., 2007), but not in guinea pig (Zagorodnyuk et al., 2003) esophageal IGLEs. Also in nonvisceral systems, Todd et al. (2003), Alvarez et al. (2004), and Persson et al. (2006) demonstrated frequent colocalization of VGLUT 2 and VGLUT $_{1}$ in primary afferent varicosities extending into the deep dorsal horn. Interestingly, afferent fibers terminating deeply in the dorsal horn originate from different types of low-threshold mechanoreceptors, and these may include visceral mechanoreceptors (Willis and Coggeshal, 2004). Thus, it could be speculated that medium- to large-sized colorectal DRG neurons expressing VGLUT 1 may subserve a mechanoreceptive function in the colorectum.

Colorectal DRG neurons also express a number of neurochemical markers associated with nociception. For example, the transient receptor potential cation channel, subfamily V, member 1 (TRPV1), a nonselective cation channel activated by $\mathrm{pH}$, heat, and capsaicin (Caterina et al., 1997; Tominaga et al., 1998), is reportedly expressed in a large proportion of colorectal DRG neurons in both rat (Christianson et al., 2006; Chaban, 2008) and mouse (Robinson et al., 2004; Christianson et al., 2006). P2X purinoceptor $3\left(\mathrm{P} 2 \mathrm{X}_{3}\right)$, a purinoceptor that has also been implicated in nociception (Wirkner et al., 2007), particularly in visceral organs (Shinoda et al., 2009; Burnstock, 2009b), is also expressed by a proportion of colorectal DRG neurons (Robinson et al., 2004). Because the great majority of extrinsic colorectal neurons described here exhibited $\mathrm{VGLUT}_{2}-\mathrm{LI}$, it is likely that they also coexpress TRPV1 and/or $\mathrm{P}_{2} \mathrm{X}_{3}$ (in addition to other receptors or channels not studied here), suggesting a relevant role for this VGLUT in the physiopathology of visceral disorders associated with discomfort and pain. Importantly, coexpression of VGLUT 2 with TRPV1 
has been previously reported in nerve fibers terminating in the mouse rectum (Spencer et al., 2008).

We could not assess the presence of VGLUT 3 protein in DRG and autonomic neurons, and their colorectal projections. Commercially available antibodies regularly used to study VGLUT $_{3}$-expressing nerve fibers in the central nervous system are largely ineffective in the study of DRG somata and their axonal projections (however, we are currently analyzing colorectal neurons in transgenic mice that express eGFP under control of $\mathrm{VGLUT}_{3}$ regulatory sequences, and exploring the expression of VGLUT $_{3}$ mRNA in lumbosacral DRG neurons through riboprobe in situ hybridization).

\section{Glutamatergic nerve terminals in the colorectum}

Here we show that VGLUT 2 -LI is observed in the form of abundant varicosities around unstained colorectal myenteric plexus neurons, in agreement with a similar description in the guinea pig small intestine for glutamate-LI (Liu et al., 1997). In contrast, the expression of VGLUT $_{1}$ in nerve fibers was very discrete. In support, Olsson et al. (2004) showed that $\approx 3 \%$ of anterogradely traced guinea pig rectal nerve varicosities terminating in the myenteric plexus contain $\mathrm{VGLUT}_{1}$, whereas $\approx 11 \%$ exhibit $\mathrm{VGLUT}_{2}$-LI, suggesting that VGLUT $_{2}$ may be the most relevant VGLUT in mouse colorectal physiology. Similarly, unidentified L4-5 DRG neurons, as well as hairy and glabrous skin nerve terminals in the mouse (Brumovsky et al., 2007), express more VGLUT 2 than VGLUT 1 . The LSC and MPG, both of which are important contributors of nerve fibers in the colorectum (Furness, 2006), could be additional sources of VGLUTs. However, analysis of these two ganglia in the present study only revealed the rare occurrence of VGLUT $_{2}$-IR neurons in the MPG.

Basal as well as stimulated (electrical and chemical) release of glutamate from longitudinal muscle myenteric plexus has been shown in the guinea pig ileum, presumably from enteric neurons (Wiley et al., 1991; Sinský and Donnerer, 1998). The abundance of VGLUT 2 in colorectal nerve fibers, most likely originating in $\mathrm{VGLUT}_{2}$-expressing DRG colorectal neurons shown here, suggests also an important contribution by extrinsic sources to the presence and action of glutamate in the gut. In fact, electrical stimulation of the sciatic nerve elicits the release of glutamate in the hindpaw skin of rat (deGroot et al., 2000).

In accordance with the peptidergic nature of the majority of colorectal DRG neurons, we found a high degree of coexpression of CGRP and $\mathrm{VGLUT}_{2}$ in nerve fibers innervating the colorectal mucosa. However, most VGLUT 2 and CGRP-IR fibers located in areas of the myenteric plexus appear to belong to different nerve populations. This is intriguing and could imply that nonpeptidergic VGLUT 2 -IR colorectal DRG neurons selectively innervate the myenteric plexus. Supporting this idea, it has been reported that VGLUT $_{2}$-containing varicosities in the esophageal myenteric plexus of rat are not CGRP-IR (Raab and Neuhuber, 2003). However, one further source of VGLUT $_{2}$ could be myenteric plexus neurons themselves (see below).

\section{A small proportion of myenteric plexus neurons in the mouse colorectum expresses VGLUT $_{2}$}

The presence of glutamate in rodent enteric neurons has been previously described in small intestine myenteric (Liu et al., 1997; Kirchgessner et al., 1997) and sub-mucosal (Liu et al., 1997; Kirchgessner, 2001) plexuses from rat (Liu et al., 1997) and guinea pig (Liu et al., 1997; Kirchgessner et al., 1997), as well as in myenteric ganglia of the rat stomach (Tsai et al., 1994). Many of these neurons were shown to express the plasma membrane glutamate transporter EEAC1 (Rothstein et al., 1994; Liu et al., 1997; Kirchgessner et al., 1997), suggesting glutamate reuptake mechanisms. In humans the presence of glutamate has been 
reported in the submucosal and myenteric plexus as well as in nerve fibers innervating the circular muscle layer of the large intestine (Giaroni et al., 2003).

Evidence for the expression of VGLUTs in enteric neurons has been somewhat controversial. On the one hand, the expression of VGLUT $_{2}$ has been suggested in ileal enteric neurons from different species (Tong et al., 2001) as well as in mouse esophagus (Raab and Neuhuber, 2005). VGLUT 1 was found in cholinergic and nitrergic neurons in rat (Raab and Neuhuber, 2003, 2004; Ewald et al., 2006) and mouse (Kraus et al., 2007) esophageal myenteric plexus. Moreover, expression of all three VGLUTs was shown in human small intestine myenteric plexus neurons, interganglionic varicose fibers, and perisomatic puncta (suggesting early gestational regulation; Linke et al., 2008). On the other hand, studies in guinea pig (Raab and Neuhuber, 2003, 2004; Zagorodnyuk et al., 2003; Ewald et al., 2006) esophagus and guinea pig rectum (Olsson et al., 2004), failed to detect VGLUT $_{1}$ or VGLUT $_{2}$ in enteric neurons.

Here we found evidence for the synthesis of VGLUT 2 in only a limited number of mouse colorectal myenteric plexus neurons. Immunoreactivity for this VGLUT was only observed in a small population of neurons scattered throughout the plexus. Because it is possible that the presence of VGLUT $_{2}-\mathrm{LI}$ in the soma of myenteric plexus neurons was derived from the endocytic internalization of VGLUTs after their release from primary afferent fibers (Fremeau et al., 2001), we carried out in situ hybridization studies to investigate the potential synthesis of VGLUTs in these neurons. We found that some neurons exhibited VGLUT $_{2}$ mRNA, but not VGLUT 1 mRNA, supporting the idea of synthesis of VGLUTs in some intrinsic mouse colorectum neurons. The phenotype of the $\mathrm{VGLUT}_{2}$-containing mouse myenteric plexus neurons remains unknown. They could be glial instead of neuronal profiles, although in the mouse and rat esophagus $\mathrm{VGLUT}_{2}$ myenteric plexus neurons lack the classical glial marker GFAP (Raab and Neuhuber, 2004). Moreover, Liu et al. (1997) often noted glutamate coexpression in enteric neurons expressing substance $\mathrm{P}$ or choline acetyltransferase in the small intestine of guinea pig and rat.

\section{Potential sites of action of glutamate released from VGLUT-expressing colorectal DRG and enteric neurons}

There is limited information about the expression of glutamatergic receptors in colorectal extrinsic (afferent) neurons. However, expression of several subunits of the excitatory NMDA receptor have been identified in the majority of rat DRG neurons from T9 to L6 (Sato et al., 1993; McRoberts et al., 2001; Marvizon et al., 2002). In support, more than 70\% of retrogradely labeled, cultured rat colorectal DRG neurons responded to NMDA with an increase in intracellular calcium content (McRoberts et al., 2001). Moreover, superfusion of rat colorectal tissue sections with NMDA and serine stimulates the outflow of SP- and CGRP-LIs, an effect abolished by the addition of capsaicin and presumably occurring in TRPV1-expressing primary afferents (McRoberts et al., 2001). Altogether, the extensive expression of VGLUT 2 (and therefore possibly also glutamate) in colorectal DRG neurons in the mouse suggests that NMDA receptors expressed in colorectal afferent terminals may have a role as auto- and/or heteroreceptors.

Enteric neurons expressing NMDA receptors have also been shown in rat colorectum (Burns et al., 1994; McRoberts et al., 2001; Del Valle-Pinero et al., 2007) and stomach (Burns et al., 1994). In the guinea pig ileum, application of L-glutamate or NMDA agonists exerts an excitatory action on muscle contraction, an effect largely dependent on the activation of myenteric plexus neurons (Wiley et al., 1991; Sinský and Donnerer, 1998; Kirchgessner, 2001). In humans, NR1, the most ubiquitous NMDA receptor subunit, was localized in cholinergic neurons as well as to glia in the large intestine (Giaroni et al., 2003). In addition, other glutamatergic receptors, including mGluR4, were found in normal colonic crypt 
epithelium and myenteric plexus neurons in human (Chang et al., 2005). Finally, pharmacological and morphological evidence also supports the presence of group I metabotropic glutamate receptors in submucosal and myenteric plexus neurons of the guinea pig, rat, and mouse colorectum (Nasser et al., 2007).

\section{Glutamate and colorectal discomfort, pain, and motility}

Several lines of evidence support a role for glutamate and its receptors in visceral sensation and nociception, acting at both central and peripheral sites. Thus, intrathecal lumbar administration of NMDA facilitates the response to colorectal distension in the naïve rat (Kolhekar and Gebhart, 1994, 1996). Conversely, hypersensitivity induced by repeated colorectal distension (Gaudreau and Plourde, 2004) or intracolonic application of inflammogens such as zymosan (Coutinho et al., 1996, 1998) or turpentine (Ide et al., 1997) is significantly attenuated by spinal (Coutinho et al., 1996; Ide et al., 1997) or ventral medulla (Coutinho et al., 1998) microinjection of NMDA receptor antagonists. Moreover, systemic application of memantine, a noncompetitive, peripherally acting NMDA receptor antagonist, reduces the behavioral response to noxious colorectal distension in conscious rats (McRoberts et al., 2001).

The behavioral events described above are at least partially dependent on the modulation of primary afferent activity. NMDA-induced CGRP release from rat spinal cord slices receiving input from DRG neurons innervating the colon has been shown to significantly increase in colitis (Li et al., 2006). Moreover, trinitrobenzene sulfonic acid (TNBS)-induced colitis in rats results in an increased NMDA current density in colorectal and noncolorectal DRG neurons, most likely through the upregulation and phosphorylation of the NR2B subunit ( $\mathrm{Li}$ et al., 2006). Peripheral activation of ionotropic receptors eliciting excitatory effects has also been shown in the peripheral endings of rat colorectum (McRoberts et al., 2001) and mouse esophagus (Page et al., 2005), further supporting the involvement of the glutamatergic system in colorectal hypersensitivity. Metabotropic glutamate receptors are also involved in visceral hypersensitivity. mGluR5 (group I) antagonists inhibit colorectal distension-evoked visceromotor and cardiovascular responses in conscious rats, at least partially through an effect on peripheral afferent endings (Lindström et al., 2008); however, central effects are also likely (Zhu et al., 2005).

Glutamate receptor activation in enteric neurons can modulate the physiology of the distal gut. Thus, the activation of ionotropic as well as metabotropic (Jankovic et al., 1999; Giaroni et al., 2000) receptors in the rat rectum (Jankovic et al., 1999) and guinea pig colon (Giaroni et al., 2000) induces strong concentration-dependent contractions. Also, selective upregulation (Zhou et al., 2006b) and phosphorylation (Zhou et al., 2006a) of NMDA receptors in myenteric plexus neurons after TNBS-induced colitis has been reported in rats, suggesting a contribution of the enteric nervous system to the physiopathology of colorectal motility and nociception. In support, a recent study shows that NMDA receptor antagonists reduce the motility and inflammatory response in TNBS-treated rats (Varga et al., 2010).

\section{VGLUTs as a pharmacological target for the modulation of visceral sensation and pain}

Functional gastrointestinal disorders are characterized by altered motility, discomfort, pain, and hypersensitivity in both the organ (e.g., to balloon distension) and its area of somatic referral, typically expressed as increased tenderness to palpation. These disorders are notoriously difficult to manage and there is thus a need to develop novel therapeutic approaches. The results presented here not only highlight the importance of the glutamatergic system in the mouse colorectum, but also suggest that $\mathrm{VGLUT}_{2}$, by far the most abundantly expressed VGLUT, may be a potentially interesting pharmacological target for the modulation of visceral pain and hypersensitivity. Because glutamate and its receptors 
have been implicated in inflammatory and neuropathic pain, several glutamatergic receptor antagonists have been tested in rodents and humans. However, despite encouraging antihyperalgesic effects, these compounds have been associated with undesired adverse effects (Sawynok, 2003; Carlton, 2009; Finch et al., 2009; Sigtermans et al., 2009).

A different strategy for central and peripheral modulation of glutamatergic signaling could be blockade of VGLUT activity. Recently synthesized VGLUT inhibitors have demonstrated high in vitro efficacy (Carrigan et al., 2002; Patel et al., 2007). Unfortunately, selective VGLUT inhibitors have yet to be reported. However, in support of their potential usefulness, a $50 \%$ reduction in VGLUT 2 protein expression in heterozygous VGLUT $_{2}$ null mice was associated with reduced/attenuated mechanical and cold hyperalgesia in the spared nerve injury model, while leaving unaffected other types of sensory processing, including acute nociception and inflammatory hyperalgesia (Moechars et al., 2006; Leo et al., 2009). This effect was not replicated in heterozygote VGLUT $_{1}$ null mutants, suggesting the importance of VGLUT $_{2}$ in glutamatergic signaling and neuropathic pain (Leo et al., 2009). More recently, the targeted deletion of VGLUT 2 in TRPV1 (Lagerström et al., 2010) or the sodium channel $\mathrm{Na}(\mathrm{v}) 1.8$-positive sensory neurons (Lagerström et al., 2011), revealed decreased responsiveness to thermal (Lager-ström et al., 2010), mechanical, and inflammatory non-visceral pain (Lagerström et al., 2011). Similar mechanisms could take place in visceral systems, as colorectal neurons express TRPV1 (Christianson et al., 2006; Chaban, 2008), and a role for $\mathrm{Na}(\mathrm{v}) 1.8$ in visceral pain and hyperalgesia was previously reported (Laird et al., 2002). It is unclear if the effects on neuropathy-induced hypersensitivity observed in VGLUT $_{2}$ heterozygous mice depend on peripheral or central mechanisms or both. However, the abundance of $\mathrm{VGLUT}_{2}$ in nonvisceral (Brumovsky et al., 2007) and colorectal primary afferent neurons (demonstrated here) suggests that a reduction in its amount per vesicle could have profound effects on the size of glutamatergic quanta (Williams, 1997; Daniels et al., 2004; Moechars et al., 2006), and thus alter neurotransmission mechanisms, both at the target organ and spinal levels.

In conclusion, we present a systematic analysis of the expression of VGLUT 1 and VGLUT $_{2}$ in DRG neurons giving rise to colorectal afferents in the mouse. Contributions of the enteric and autonomic nervous systems were also addressed. The results reveal that $\mathrm{VGLUT}_{2}$, as compared to $\mathrm{VGLUT}_{1}$, is the most abundant VGLUT in extrinsic nerve terminals in the colorectum, suggesting the presence of glutamate and its potential release upon adequate stimuli. Currently ongoing studies in our laboratory will determine if $\mathrm{VGLUT}_{3}$ is also expressed by colorectal DRG neurons. Finally, the discrete number of myenteric neurons expressing $\mathrm{VGLUT}_{2}$ suggests that either very few enteric colorectal neurons in the mouse are glutamatergic or that VGLUT 3 (or another unidentified VGLUT) participates in the incorporation of glutamate in enteric neurons in this organ.

\title{
Acknowledgments
}

Grant sponsor: National Institutes of Health (NIH); Grant number: NS19912 (to G.G.); Grant sponsor: IASP Early Career Research Award (to P.B.).

We thank Dr. Akiya Watakabe, National Institute for Basic Biology, Okazaki, Japan, for the generous donation of the VGLUT 1 and VGLUT2 riboprobes. We also thank Mrs. Pamela Cornuet and Mr. Tim McMurray for excellent technical assistance, and Ms. Ann Hemmerle for assistance with some of the illustrations.

\section{Abbreviations}

\author{
BT Biotinyl tyramide \\ CGRP Calcitonin gene-related peptide
}




\begin{tabular}{ll} 
DRG & Dorsal root ganglion \\
EGFP & Enhanced green fluorescent protein \\
FB & Fast blue \\
FITC & Fluorothiocyanate \\
IB4 & Isolectin B4 \\
IGLES & Intraganglionic laminar endings \\
IR & Immunoreactive \\
L & Lumbar \\
LI & Like-immunoreactivity \\
LS & Lumbosacral \\
LSC & Lumbar sympathetic chain \\
MPG & Major pelvic ganglion \\
NPs & Neuron profiles \\
P2X & P2X purinoceptor 3 \\
PBS & Phosphate-buffered saline \\
PI & Propidium iodide \\
RT & Room temperature \\
SEM & Standard error of the mean \\
T & Thoracic \\
TL & Thoracolumbar \\
TRITC & Tetramethyl rhodamine isothiocyanate \\
TRPV1 & Transient receptor potential cation channel, subfamily V, member 1 \\
TSA & Tyramide signal amplification \\
VGLUTs & Vesicular glutamate transporters \\
& \\
\hline TURE CITED & \\
\hline
\end{tabular}

Abercrombie M. Estimation of nuclear population from microtome sections. Anat Rec. 1946; 94:239247. [PubMed: 21015608]

Adams JC. Biotin amplification of biotin and horseradish peroxidase signals in histochemical stains. J Histochem Cytochem. 1992; 40:1457-1463. [PubMed: 1527370]

Aihara Y, Mashima H, Onda H, Hisano S, Kasuya H, Hori T, Yamada S, Tomura H, Yamada Y, Inoue I, Kojima I, Takeda J. Molecular cloning of a novel brain-type $\mathrm{Na}(+)$-dependent inorganic phosphate cotransporter. J Neurochem. 2000; 74:2622-2625. [PubMed: 10820226]

Alvarez FJ, Villalba RM, Zerda R, Schneider SP. Vesicular glutamate transporters in the spinal cord, with special reference to sensory primary afferent synapses. J Comp Neurol. 2004; 472:257-280. [PubMed: 15065123]

Anlauf E, Derouiche A. Astrocytic exocytosis vesicles and glutamate: a high-resolution immunofluorescence study. Glia. 2005; 49:96-106. [PubMed: 15390103]

Bellocchio EE, Reimer RJ, Fremeau RT Jr, Edwards RH. Uptake of glutamate into synaptic vesicles by an inorganic phosphate transporter. Science. 2000; 289:957-960. [PubMed: 10938000] 
Bennett DL, Dmietrieva N, Priestley JV, Clary D, McMahon SB. trkA, CGRP and IB4 expression in retrogradely labelled cutaneous and visceral primary sensory neurones in the rat. Neurosci Lett. 1996; 206:33-36. [PubMed: 8848275]

Berthoud HR, Patterson LM, Neumann F, Neuhuber WL. Distribution and structure of vagal afferent intraganglionic laminar endings (IGLEs) in the rat gastrointestinal tract. Anat Embryol (Berl). 1997; 195:183-191. [PubMed: 9045988]

Blackshaw LA, Brookes SJ, Grundy D, Schemann M. Sensory transmission in the gastrointestinal tract. Neurogastroenterol Motil. 2007; 19:1-19. [PubMed: 17280582]

Boulland JL, Qureshi T, Seal RP, Rafiki A, Gundersen V, Bergersen LH, Fremeau RT Jr, Edwards RH, Storm-Mathisen J, Chaudhry FA. Expression of the vesicular glutamate transporters during development indicates the widespread corelease of multiple neurotransmitters. J Comp Neurol. 2004; 480:264-280. [PubMed: 15515175]

Brierley SM, Jones RC III, Gebhart GF, Blackshaw LA. Splanchnic and pelvic mechanosensory afferents signal different qualities of colonic stimuli in mice. Gastroenterology. 2004; 127:166178. [PubMed: 15236183]

Brierley SM, Carter R, Jones W III, Xu L, Robinson DR, Hicks GA, Gebhart GF, Blackshaw LA. Differential chemosensory function and receptor expression of splanchnic and pelvic colonic afferents in mice. J Physiol. 2005a; 567:267-281. [PubMed: 15946967]

Brierley SM, Jones RC III, Xu L, Gebhart GF, Blackshaw LA. Activation of splanchnic and pelvic colonic afferents by bradykinin in mice. Neurogastroenterol Motil. 2005b; 17:854-862. [PubMed: 16336501]

Broman, J.; Hassel, B.; Rinvik, E.; Ottersen, OP. Biochemistry and anatomy of transmitter glutamate. Amsterdam: Elsevier; 2000. p. 1-44.

Brumovsky PR, Gebhart GF. Visceral organ cross-sensitization - an integrated perspective. Auton Neurosci. 2010; 153:106-115. [PubMed: 19679518]

Brumovsky P, Watanabe M, Hökfelt T. Expression of the vesicular glutamate transporters-1 and -2 in adult mouse dorsal root ganglia and spinal cord and their regulation by nerve injury. Neuroscience. 2007; 147:469-490. [PubMed: 17577523]

Burns GA, Stephens KE, Benson JA. Expression of mRNA for the N-methyl-D-aspartate (NMDAR1) receptor by the enteric neurons of the rat. Neurosci Lett. 1994; 170:87-90. [PubMed: 8041519]

Burnstock G. Autonomic neurotransmission: 60 years since Sir Henry Dale. Annu Rev Pharmacol Toxicol. 2009a; 49:1-30. [PubMed: 18834312]

Burnstock G. Purinergic mechanosensory transduction and visceral pain. Mol Pain. 2009b; 5:69. [PubMed: 19948030]

Carlton SM. Peripheral NMDA receptors revisited - hope floats. Pain. 2009; 146:1-2. [PubMed: 19767145]

Carrigan CN, Bartlett RD, Esslinger CS, Cybulski KA, Tongcharoensirikul P, Bridges RJ, Thompson CM. Synthesis and in vitro pharmacology of substituted quinoline-2,4-dicarboxylic acids as inhibitors of vesicular glutamate transport. J Med Chem. 2002; 45:2260-2276. [PubMed: 12014964]

Caterina MJ, Schumacher MA, Tominaga M, Rosen TA, Levine JD, Julius D. The capsaicin receptor: a heat-activated ion channel in the pain pathway. Nature. 1997; 389:816-824. [PubMed: 9349813]

Chaban VV. Visceral sensory neurons that innervate both uterus and colon express nociceptive TRPv1 and P2X3 receptors in rats. Ethn Dis. 2008; 18:S2-S4. [PubMed: 18646315]

Chang HJ, Yoo BC, Lim SB, Jeong SY, Kim WH, Park JG. Metabotropic glutamate receptor 4 expression in colorectal carcinoma and its prognostic significance. Clin Cancer Res. 2005; 11:3288-3295. [PubMed: 15867225]

Christianson JA, Traub RJ, Davis BM. Differences in spinal distribution and neurochemical phenotype of colonic afferents in mouse and rat. J Comp Neurol. 2006; 494:246-259. [PubMed: 16320237]

Coons AH. Fluorescent antibody methods. Gen Cytochem Methods. 1958; 1:399-422. [PubMed: 13574437]

Corbett EK, Sinfield JK, McWilliam PN, Deuchars J, Batten TF. Differential expression of vesicular glutamate transporters by vagal afferent terminals in rat nucleus of the solitary tract: projections 
from the heart preferentially express vesicular glutamate transporter 1. Neuroscience. 2005; 135:133-145. [PubMed: 16084661]

Coutinho SV, Meller ST, Gebhart GF. Intracolonic zymosan produces visceral hyperalgesia in the rat that is mediated by spinal NMDA and non-NMDA receptors. Brain Res. 1996; 736:7-15. [PubMed: 8930303]

Coutinho SV, Urban MO, Gebhart GF. Role of glutamate receptors and nitric oxide in the rostral ventromedial medulla in visceral hyperalgesia. Pain. 1998; 78:59-69. [PubMed: 9822212]

Danbolt NC. Glutamate uptake. Prog Neurobiol. 2001; 65:1-105. [PubMed: 11369436]

Daniels RW, Collins CA, Gelfand MV, Dant J, Brooks ES, Krantz DE, DiAntonio A. Increased expression of the Drosophila vesicular glutamate transporter leads to excess glutamate release and a compensatory decrease in quantal content. J Neurosci. 2004; 24:10466-10474. [PubMed: 15548661]

De Biasi S, Rustioni A. Glutamate and substance P coexist in primary afferent terminals in the superficial laminae of spinal cord. Proc Natl Acad Sci U S A. 1988; 85:7820-7824. [PubMed: 2459717]

deGroot J, Zhou S, Carlton SM. Peripheral glutamate release in the hindpaw following low and high intensity sciatic stimulation. Neuroreport. 2000; 11:497-502. [PubMed: 10718302]

Del Valle-Pinero AY, Suckow SK, Zhou Q, Perez FM, Verne GN, Caudle RM. Expression of the Nmethyl-D-aspartate receptor NR1 splice variants and NR2 subunit subtypes in the rat colon. Neuroscience. 2007; 147:164-173. [PubMed: 17509768]

Dickerson JW, Hemmerle AM, Numan S, Lundgren KH, Seroogy KB. Decreased expression of ErbB4 and tyrosine hydroxylase mRNA and protein in the ventral midbrain of aged rats. Neuroscience. 2009; 163:482-489. [PubMed: 19505538]

Ewald P, Neuhuber WL, Raab M. Vesicular glutamate transporter 1 immunoreactivity in extrinsic and intrinsic innervation of the rat esophagus. Histochem Cell Biol. 2006; 125:377-395. [PubMed: 16231188]

Finch PM, Knudsen L, Drummond PD. Reduction of allodynia in patients with complex regional pain syndrome: a double-blind placebo-controlled trial of topical ketamine. Pain. 2009; 146:18-25. [PubMed: 19703730]

Fonnum F. Glutamate: a neurotransmitter in mammalian brain. J Neurochem. 1984; 42:1-11. [PubMed: 6139418]

Fremeau RT Jr, Troyer MD, Pahner I, Nygaard GO, Tran CH, Reimer RJ, Bellocchio EE, Fortin D, Storm-Mathisen J, Edwards RH. The expression of vesicular glutamate transporters defines two classes of excitatory synapse. Neuron. 2001; 31:247-260. [PubMed: 11502256]

Fremeau RT Jr, Burman J, Qureshi T, Tran CH, Proctor J, Johnson J, Zhang H, Sulzer D, Copenhagen DR, Storm-Mathisen J, Reimer RJ, Chaudhry FA, Edwards RH. The identification of vesicular glutamate transporter 3 suggests novel modes of signaling by glutamate. Proc Natl Acad Sci U S A. 2002; 99:14488-14493. [PubMed: 12388773]

Fremeau RT Jr, Voglmaier S, Seal RP, Edwards RH. VGLUTs define subsets of excitatory neurons and suggest novel roles for glutamate. Trends Neurosci. 2004; 27:98-103. [PubMed: 15102489]

Furness JB. The organisation of the autonomic nervous system: peripheral connections. Auton Neurosci. 2006; 130:1-5. [PubMed: 16798102]

Furness JB, Jones C, Nurgali K, Clerc N. Intrinsic primary afferent neurons and nerve circuits within the intestine. Prog Neurobiol. 2004; 72:143-164. [PubMed: 15063530]

Gaudreau GA, Plourde V. Involvement of N-methyl-d-aspartate (NMDA) receptors in a rat model of visceral hypersensitivity. Behav Brain Res. 2004; 150:185-189. [PubMed: 15033291]

Gebhart, GF.; Robinson, DR.; La, J-H.; Hökfelt, T.; Watanabe, M.; Brumovsky, P. Expression of vesicular glutamate transporters in neurons innervating the mouse colon. Gebhart, GF.; Robinson, DR.; La, J-H.; Hökfelt, T.; Watanabe, M.; Brumovsky, P., editors. Society for Neuroscience; Washington, DC: 2008.

Giaroni C, Zanetti E, Marino F, Cosentino M, Senaldi A, Somaini L, Ferrari M, Bombelli R, Lecchini S, Frigo G. Glutamate receptors of the AMPA type modulate neurotransmitter release and peristalsis in the guinea-pig isolated colon. Life Sci. 2000; 67:1747-1757. [PubMed: 11021359] 
Giaroni C, Zanetti E, Chiaravalli AM, Albarello L, Dominioni L, Capella C, Lecchini S, Frigo G. Evidence for a glutamatergic modulation of the cholinergic function in the human enteric nervous system via NMDA receptors. Eur J Pharmacol. 2003; 476:63-69. [PubMed: 12969750]

Guillery RW. On counting and counting errors. J Comp Neurol. 2002; 447:1-7. [PubMed: 11967890]

Hökfelt T, Johansson O, Goldstein M. Chemical anatomy of the brain. Science. 1984; 225:1326-1334. [PubMed: 6147896]

Hwang SJ, Burette A, Rustioni A, Valtschanoff JG. Vanilloid receptor VR1-positive primary afferents are glutamatergic and contact spinal neurons that co-express neurokinin receptor NK1 and glutamate receptors. J Neurocytol. 2004; 33:321-329. [PubMed: 15475687]

Ide Y, Maehara Y, Tsukahara S, Kitahata LM, Collins JG. The effects of an intrathecal NMDA antagonist (AP5) on the behavioral changes induced by colorectal inflammation with turpentine in rats. Life Sci. 1997; 60:1359-1363. [PubMed: 9096256]

Jankovic SM, Milovanovic D, Matovic M, Iric-Cupic V. The effects of excitatory amino acids on isolated gut segments of the rat. Pharmacol Res. 1999; 39:143-148. [PubMed: 10072705]

Kaneko T, Fujiyama F. Complementary distribution of vesicular glutamate transporters in the central nervous system. Neurosci Res. 2002; 42:243-250. [PubMed: 11985876]

Kaneko T, Akiyama H, Nagatsu I, Mizuno N. Immunohistochemical demonstration of glutaminase in catecholaminergic and serotoninergic neurons of rat brain. Brain Res. 1990; 507:151-154. [PubMed: 1967973]

Kanner BI, Schuldiner S. Mechanism of transport and storage of neurotransmitters. CRC Crit Rev Biochem. 1987; 22:1-38. [PubMed: 2888595]

Kawamura Y, Fukaya M, Maejima T, Yoshida T, Miura E, Watanabe M, Ohno-Shosaku T, Kano M. The CB1 cannabinoid receptor is the major cannabinoid receptor at excitatory presynaptic sites in the hippocampus and cerebellum. J Neurosci. 2006; 26:2991-3001. [PubMed: 16540577]

Keast JR, De Groat WC. Segmental distribution and peptide content of primary afferent neurons innervating the urogenital organs and colon of male rats. J Comp Neurol. 1992; 319:615-623. [PubMed: 1619047]

Kirchgessner AL. Glutamate in the enteric nervous system. Curr Opin Pharmacol. 2001; 1:591-596. [PubMed: 11757814]

Kirchgessner AL, Liu MT, Alcantara F. Excitotoxicity in the enteric nervous system. J Neurosci. 1997; 17:8804-8816. [PubMed: 9348349]

Kolhekar R, Gebhart GF. NMDA and quisqualate modulation of visceral nociception in the rat. Brain Res. 1994; 651:215-226. [PubMed: 7922569]

Kolhekar R, Gebhart GF. Modulation of spinal visceral nociceptive transmission by NMDA receptor activation in the rat. J Neurophysiol. 1996; 75:2344-2353. [PubMed: 8793747]

Kraus T, Neuhuber WL, Raab M. Distribution of vesicular glutamate transporter 1 (VGLUT1) in the mouse esophagus. Cell Tissue Res. 2007; 329:205-219. [PubMed: 17508221]

Laird JM, Souslova V, Wood JN, Cervero F. Deficits in visceral pain and referred hyperalgesia in Nav1,8 (SNS/ PN3)-null mice. J Neurosci. 2002; 22:8352-8356. [PubMed: 12351708]

Landry M, Bouali-Benazzouz R, El MS, Ravassard P, Nagy F. Expression of vesicular glutamate transporters in rat lumbar spinal cord, with a note on dorsal root ganglia. J Comp Neurol. 2004; 468:380-394. [PubMed: 14681932]

Leo S, Moechars D, Callaerts-Vegh Z, D'Hooge R, Meert T. Impairment of VGLUT2 but not VGLUT1 signaling reduces neuropathy-induced hypersensitivity. Eur J Pain. 2009; 13:1008-1017. [PubMed: 19171494]

Li JL, Xiong KH, Dong YL, Fujiyama F, Kaneko T, Mizuno N. Vesicular glutamate transporters, VGluT1 and VGluT2, in the trigeminal ganglion neurons of the rat, with special reference to coexpression. J Comp Neurol. 2003; 463:212-220. [PubMed: 12815758]

Li J, McRoberts JA, Ennes HS, Trevisani M, Nicoletti P, Mittal Y, Mayer EA. Experimental colitis modulates the functional properties of NMDA receptors in dorsal root ganglia neurons. Am J Physiol Gastrointest Liver Physiol. 2006; 291:G219-G228. [PubMed: 16565418]

Liguz-Lecznar M, Skangiel-Kramska J. Vesicular glutamate transporters (VGLUTs): the three musketeers of glutamatergic system. Acta Neurobiol Exp (Wars). 2007; 67:207-218. [PubMed: 17957901] 
Lin LH, Talman WT. Vesicular glutamate transporters and neuronal nitric oxide synthase colocalize in aortic depressor afferent neurons. J Chem Neuroanat. 2006; 32:54-64. [PubMed: 16735103]

Lindström E, Brusberg M, Hughes PA, Martin CM, Brierley SM, Phillis BD, Martinsson R, Abrahamsson C, Larsson H, Martinez V, Blackshaw LA. Involvement of metabotropic glutamate 5 receptor in visceral pain. Pain. 2008; 137:295-305. [PubMed: 17937975]

Linke N, Bodi N, Resch BE, Fekete E, Bagyanszki M. Developmental pattern of three vesicular glutamate transporters in the myenteric plexus of the human fetal small intestine. Histol Histopathol. 2008; 23:979-986. [PubMed: 18498073]

Liu MT, Rothstein JD, Gershon MD, Kirchgessner AL. Glutamatergic enteric neurons. J Neurosci. 1997; 17:4764-4784. [PubMed: 9169536]

Marvizon JC, McRoberts JA, Ennes HS, Song B, Wang X, Jinton L, Corneliussen B, Mayer EA. Two $\mathrm{N}$-methyl-D-aspartate receptors in rat dorsal root ganglia with different subunit composition and localization. J Comp Neurol. 2002; 446:325-341. [PubMed: 11954032]

Mayhew TM, Gundersen HJ. If you assume, you can make an ass out of $u$ and me: a decade of the disector for setereological counting of particles in 3D space. J Anat. 1996; 188:1-15. [PubMed: 8655396]

McMahon, SB.; Priestley, JV. Nociceptor plasticity. Oxford: Oxford University Press; 2005. p. 35-64.

McRoberts JA, Coutinho SV, Marvizon JC, Grady EF, Tognetto M, Sengupta JN, Ennes HS, Chaban VV, Amadesi S, Creminon C, Lanthorn T, Geppetti P, Bunnett NW, Mayer EA. Role of peripheral N-methyl-D-aspartate (NMDA) receptors in visceral nociception in rats. Gastroenterology. 2001; 120:1737-1748. [PubMed: 11375955]

Miura E, Fukaya M, Sato T, Sugihara K, Asano M, Yoshioka K, Watanabe M. Expression and distribution of JNK/ SAPK-associated scaffold protein JSAP1 in developing and adult mouse brain. J Neurochem. 2006; 97:1431-1446. [PubMed: 16606357]

Miyazaki T, Fukaya M, Shimizu H, Watanabe M. Subtype switching of vesicular glutamate transporters at parallel fibre-Purkinje cell synapses in developing mouse cerebellum. Eur J Neurosci. 2003; 17:2563-2572. [PubMed: 12823463]

Moechars D, Weston MC, Leo S, Callaerts-Vegh Z, Goris I, Daneels G, Buist A, Cik M, van der SP, Kass S, Meert T, D’Hooge R, Rosenmund C, Hampson RM. Vesicular glutamate transporter VGLUT2 expression levels control quantal size and neuropathic pain. J Neurosci. 2006; 26:12055-12066. [PubMed: 17108179]

Montana V, Ni Y, Sunjara V, Hua X, Parpura V. Vesicular glutamate transporter-dependent glutamate release from astrocytes. J Neurosci. 2004; 24:2633-2642. [PubMed: 15028755]

Moriyama Y, Yamamoto A. Glutamatergic chemical transmission: look! Here, there, and anywhere. J Biochem. 2004; 135:155-163. [PubMed: 15047716]

Morris JL, Konig P, Shimizu T, Jobling P, Gibbins IL. Most peptide-containing sensory neurons lack proteins for exocytotic release and vesicular transport of glutamate. J Comp Neurol. 2005; 483:116. [PubMed: 15672399]

Nakamura K, Watakabe A, Hioki H, Fujiyama F, Tanaka Y, Yamamori T, Kaneko T. Transiently increased colocalization of vesicular glutamate transporters 1 and 2 at single axon terminals during postnatal development of mouse neocortex: a quantitative analysis with correlation coefficient. Eur J Neurosci. 2007; 26:3054-3067. [PubMed: 18028110]

Nasser Y, Keenan CM, Ma AC, McCafferty DM, Sharkey KA. Expression of a functional metabotropic glutamate receptor 5 on enteric glia is altered in states of inflammation. Glia. 2007; 55:859-872. [PubMed: 17405149]

Ni B, Rosteck PR Jr, Nadi NS, Paul SM. Cloning and expression of a cDNA encoding a brain-specific $\mathrm{Na}(+)$-dependent inorganic phosphate cotransporter. Proc Natl Acad Sci U S A. 1994; 91:56075611. [PubMed: 8202535]

Numan S, Gall CM, Seroogy KB. Developmental expression of neurotrophins and their receptors in postnatal rat ventral midbrain. J Mol Neurosci. 2005; 27:245-260. [PubMed: 16186635]

Oliveira AL, Hydling F, Olsson E, Shi T, Edwards RH, Fujiyama F, Kaneko T, Hokfelt T, Cullheim S, Meister B. Cellular localization of three vesicular glutamate transporter mRNAs and proteins in rat spinal cord and dorsal root ganglia. Synapse. 2003; 50:117-129. [PubMed: 12923814] 
Olsson C, Costa M, Brookes SJ. Neurochemical characterization of extrinsic innervation of the guinea pig rectum. J Comp Neurol. 2004; 470:357-371. [PubMed: 14961562]

Ottersen OP. Postembedding light- and electron microscopic immunocytochemistry of amino acids: description of a new model system allowing identical conditions for specificity testing and tissue processing. Exp Brain Res. 1987; 69:167-174. [PubMed: 3125058]

Page AJ, Young RL, Martin CM, Umaerus M, O’Donnell TA, Cooper NJ, Coldwell JR, Hulander M, Mattsson JP, Lehmann A, Blackshaw LA. Metabotropic glutamate receptors inhibit mechanosensitivity in vagal sensory neurons. Gastroenterology. 2005; 128:402-410. [PubMed: $15685551]$

Patel SA, Nagy JO, Bolstad ED, Gerdes JM, Thompson CM. Tetrapeptide inhibitors of the glutamate vesicular transporter (VGLUT). Bioorg Med Chem Lett. 2007; 17:5125-5128. [PubMed: 17662605]

Persson S, Boulland JL, Aspling M, Larsson M, Fremeau RT Jr, Edwards RH, Storm-Mathisen J, Chaudhry FA, Broman J. Distribution of vesicular glutamate transporters 1 and 2 in the rat spinal cord, with a note on the spinocervical tract. J Comp Neurol. 2006; 497:683-701. [PubMed: 16786558]

Raab M, Neuhuber WL. Vesicular glutamate transporter 2 immunoreactivity in putative vagal mechanosensor terminals of mouse and rat esophagus: indication of a local effector function? Cell Tissue Res. 2003; 312:141-148. [PubMed: 12698357]

Raab M, Neuhuber WL. Intraganglionic laminar endings and their relationships with neuronal and glial structures of myenteric ganglia in the esophagus of rat and mouse. Histochem Cell Biol. 2004; 122:445-459. [PubMed: 15378379]

Raab M, Neuhuber WL. Number and distribution of intraganglionic laminar endings in the mouse esophagus as demonstrated with two different immunohistochemical markers. J Histochem Cytochem. 2005; 53:1023-1031. [PubMed: 15923367]

Robinson DR, Gebhart GF. Inside information: the unique features of visceral sensation. Mol Interv. 2008; 8:242-253. [PubMed: 19015388]

Robinson DR, McNaughton PA, Evans ML, Hicks GA. Characterization of the primary spinal afferent innervation of the mouse colon using retrograde labelling. Neurogastroenterol Motil. 2004; 16:113-124. [PubMed: 14764211]

Rothstein JD, Martin L, Levey AI, Dykes-Hoberg M, Jin L, Wu D, Nash N, Kuncl RW. Localization of neuronal and glial glutamate transporters. Neuron. 1994; 13:713-725. [PubMed: 7917301]

Sato K, Kiyama H, Park HT, Tohyama M. AMPA, KA and NMDA receptors are expressed in the rat DRG neurones. Neuroreport. 1993; 4:1263-1265. [PubMed: 8219025]

Sawynok J. Topical and peripherally acting analgesics. Pharmacol Rev. 2003; 55:1-20. [PubMed: 12615951]

Schäfer MK, Varoqui H, Defamie N, Weihe E, Erickson JD. Molecular cloning and functional identification of mouse vesicular glutamate transporter 3 and its expression in subsets of novel excitatory neurons. J Biol Chem. 2002; 277:50734-50748. [PubMed: 12384506]

Seal RP, Wang X, Guan Y, Raja SN, Woodbury CJ, Basbaum AI, Edwards RH. Injury-induced mechanical hypersensitivity requires C-low threshold mechanoreceptors. Nature. 2009; 462:651655. [PubMed: 19915548]

Seroogy, KB.; Herman, JP. In situ hybridization approaches to the study of the nervous system. In: Turner, AJ.; Bachelard, HS., editors. Neurochemistry: a practical approach. 2. Oxford: Oxford University Press; 1997. p. 121-150.

Seroogy KB, Lundgren KH, Tran TMD, Guthrie KM, Isackson PJ, Gall CM. Dopaminergic neurons in rat ventral midbrain express brain-derived neurotrophic factor and neurotrophin-3 mRNAs. J Comp Neurol. 1994; 342:321-334. [PubMed: 7912699]

Shinoda M, Feng B, Gebhart GF. Peripheral and central P2X receptor contributions to colon mechanosensitivity and hypersensitivity in the mouse. Gastroenterology. 2009; 137:2096-2104. [PubMed: 19549524]

Sigtermans MJ, van Hilten JJ, Bauer MC, Arbous MS, Marinus J, Sarton EY, Dahan A. Ketamine produces effective and long-term pain relief in patients with complex regional pain syndrome type 1. Pain. 2009; 145:304-311. [PubMed: 19604642] 
Sinský M, Donnerer J. Evidence for a neurotransmitter role of glutamate in guinea pig myenteric plexus neurons. Neurosci Lett. 1998; 258:109-112. [PubMed: 9875539]

Spencer NJ, Kerrin A, Singer CA, Hennig GW, Gerthoffer WT, McDonnell O. Identification of capsaicin-sensitive rectal mechanoreceptors activated by rectal distension in mice. Neuroscience. 2008; 153:518-534. [PubMed: 18395992]

Storm-Mathisen J, Leknes AK, Bore AT, Vaaland JL, Edminson P, Haug FM, Ottersen OP. First visualization of glutamate and GABA in neurones by immunocytochemistry. Nature. 1983; 301:517-520. [PubMed: 6130475]

Sugiura T, Bielefeldt K, Gebhart GF. Mouse colon sensory neurons detect extracellular acidosis via TRPV1. Am J Physiol Cell Physiol. 2007; 292:C1768-C1774. [PubMed: 17251322]

Takamori S, Rhee JS, Rosenmund C, Jahn R. Identification of differentiation-associated brain-specific phosphate transporter as a second vesicular glutamate transporter (VGLUT2). J Neurosci. 2001; 21:RC182. [PubMed: 11698620]

Tan LL, Bornstein JC, Anderson CR. Distinct chemical classes of medium-sized transient receptor potential channel vanilloid 1-immunoreactive dorsal root ganglion neurons innervate the adult mouse jejunum and colon. Neuroscience. 2008; 156:334-343. [PubMed: 18706490]

Todd AJ, Hughes DI, Polgár E, Nagy GG, Mackie M, Ottersen OP, Maxwell DJ. The expression of vesicular glutamate transporters VGLUT1 and VGLUT2 in neurochemically defined axonal populations in the rat spinal cord with emphasis on the dorsal horn. Eur J Neurosci. 2003; 17:1327. [PubMed: 12534965]

Tominaga M, Caterina MJ, Malmberg AB, Rosen TA, Gilbert H, Skinner K, Raumann BE, Basbaum AI, Julius D. The cloned capsaicin receptor integrates multiple pain-producing stimuli. Neuron. 1998; 21:531-543. [PubMed: 9768840]

Tong Q, Ma J, Kirchgessner AL. Vesicular glutamate transporter 2 in the brain-gut axis. Neuroreport. 2001; 12:3929-3934. [PubMed: 11742213]

Traub RJ, Hutchcroft K, Gebhart GF. The peptide content of colonic afferents decreases following colonic inflammation. Peptides. 1999; 20:267-273. [PubMed: 10422883]

Tsai LH, Tsai W, Wu JY. Effect of L-glutamic acid on acid secretion and immunohistochemical localization of glutamatergic neurons in the rat stomach. J Neurosci Res. 1994; 38:188-195. [PubMed: 7915763]

Varga G, Erces D, Fazekas B, Fulop M, Kovacs T, Kaszaki J, Fulop F, Vecsei L, Boros M. N-MethylD-aspartate receptor antagonism decreases motility and inflammatory activation in the early phase of acute experimental colitis in the rat. Neurogastroenterol Motil. 2010; 22:217-225. e68. [PubMed: 19735360]

Wang HF, Shortland P, Park MJ, Grant G. Retrograde and transganglionic transport of horseradish peroxidase-conjugated cholera toxin B subunit, wheatgerm agglutinin and isolectin B4 from Griffonia simplicifolia I in primary afferent neurons innervating the rat urinary bladder. Neuroscience. 1998; 87:275-288. [PubMed: 9722157]

Watkins JC. L-glutamate as a central neurotransmitter: looking back. Biochem Soc Trans. 2000; 28:297-309. [PubMed: 10961913]

Wiley JW, Lu YX, Owyang C. Evidence for a glutamatergic neural pathway in the myenteric plexus. Am J Physiol. 1991; 261:G693-G700. [PubMed: 1681738]

Williams J. How does a vesicle know it is full? Neuron. 1997; 18:683-686. [PubMed: 9182793]

Willis, WD.; Coggeshall, RE. Sensory mechanisms of the spinal cord. Vol. 1. New York: Kluwer Academic/Plenum; 2004. p. 80-82.

Wirkner K, Sperlagh B, Illes P. P2X3 receptor involvement in pain states. Mol Neurobiol. 2007; 36:165-183. [PubMed: 17952660]

Zagorodnyuk VP, Chen BN, Costa M, Brookes SJ. Mechanotransduction by intraganglionic laminar endings of vagal tension receptors in the guinea-pig oesophagus. J Physiol. 2003; 553:575-587. [PubMed: 14500769]

Zhang L, Hoff AO, Wimalawansa SJ, Cote GJ, Gagel RF, Westlund KN. Arthritic calcitonin/alpha calcitonin gene-related peptide knockout mice have reduced nociceptive hypersensitivity. Pain. 2001; 89:265-273. [PubMed: 11166483] 
Zhou Q, Caudle RM, Moshiree B, Price DD, Verne GN. Phosphorylation of NMDA NR1 subunits in the myenteric plexus during TNBS induced colitis. Neurosci Lett. 2006a; 406:250-255. [PubMed: 16942839]

Zhou Q, Caudle RM, Price DD, Del Valle-Pinero AY, Verne GN. Selective up-regulation of NMDANR1 receptor expression in myenteric plexus after TNBS induced colitis in rats. Mol Pain. 2006b; 2:3. [PubMed: 16417630]

Zhu CZ, Hsieh G, EI-Kouhen O, Wilson SG, Mikusa JP, Hollings-worth PR, Chang R, Moreland RB, Brioni J, Decker MW, Honore P. Role of central and peripheral mGluR5 receptors in postoperative pain in rats. Pain. 2005; 114:195-202. [PubMed: 15733645] 


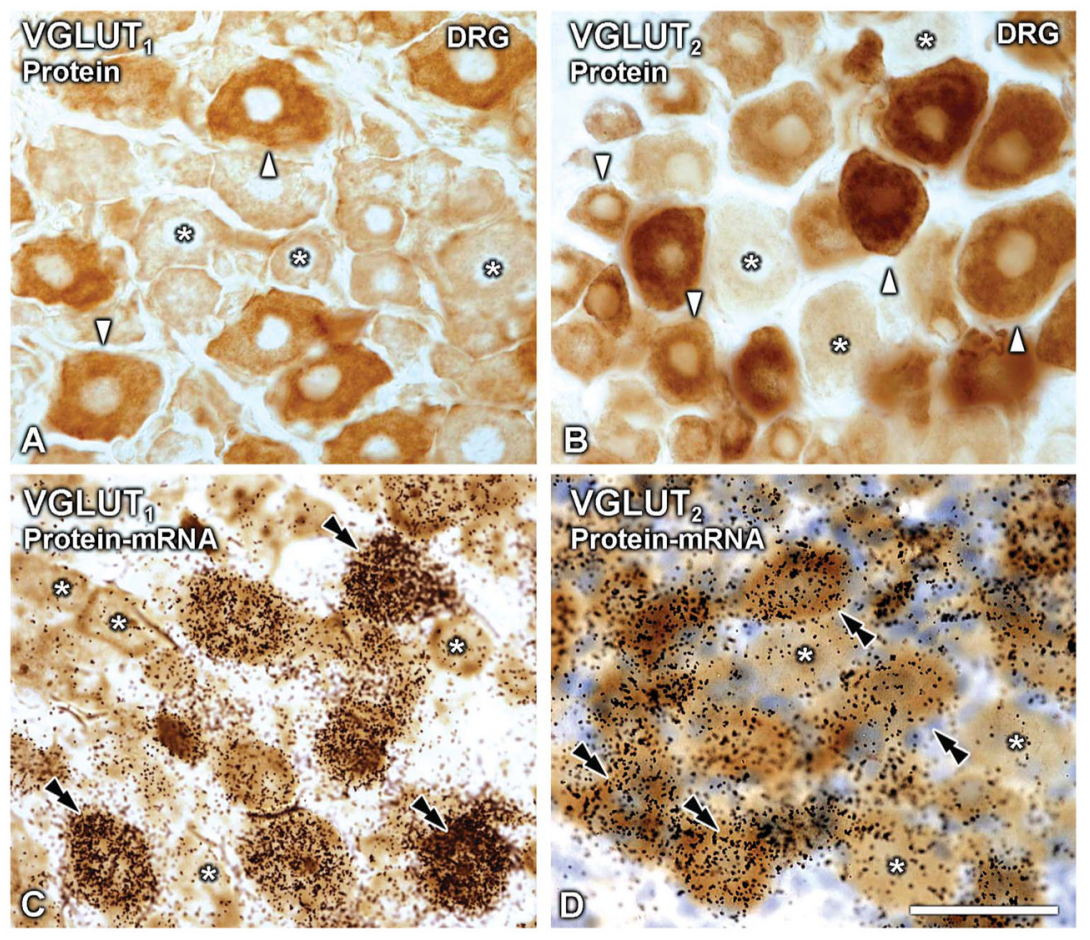

Figure 1.

Brightfield optical photomicrographs of lumbar DRG sections, incubated with antiserum to $\operatorname{VGLUT}_{1}(\mathbf{A})$ or $\operatorname{VGLUT}_{2}(\mathbf{B})$, or after coincubation with antibodies and antisense riboprobes against $\mathrm{VGLUT}_{1}(\mathbf{C})$ or $\mathrm{VGLUT}_{2}(\mathbf{D})$ protein and mRNA, respectively. A, B: A

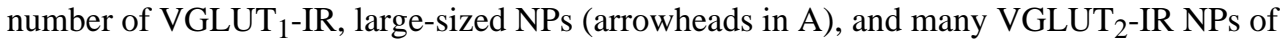
different sizes (arrowheads in B) are detected in DRG sections. NPs lacking any of the two VGLUTs can be seen (asterisks). C, D: Combined riboprobe in situ hybridizationimmunohistochemistry experiments reveal that both mRNA and protein for $\mathrm{VGLUT}_{1}$ or VGLUT $_{2}$ are colocalized in the same DRG NPs (double black arrowheads in C, D, respectively). Neurons lacking both types of signal are also present (asterisks). Scale bar = $50 \mu \mathrm{m}$. [Color figure can be viewed in the online issue, which is available at wileyonlinelibrary.com.] 

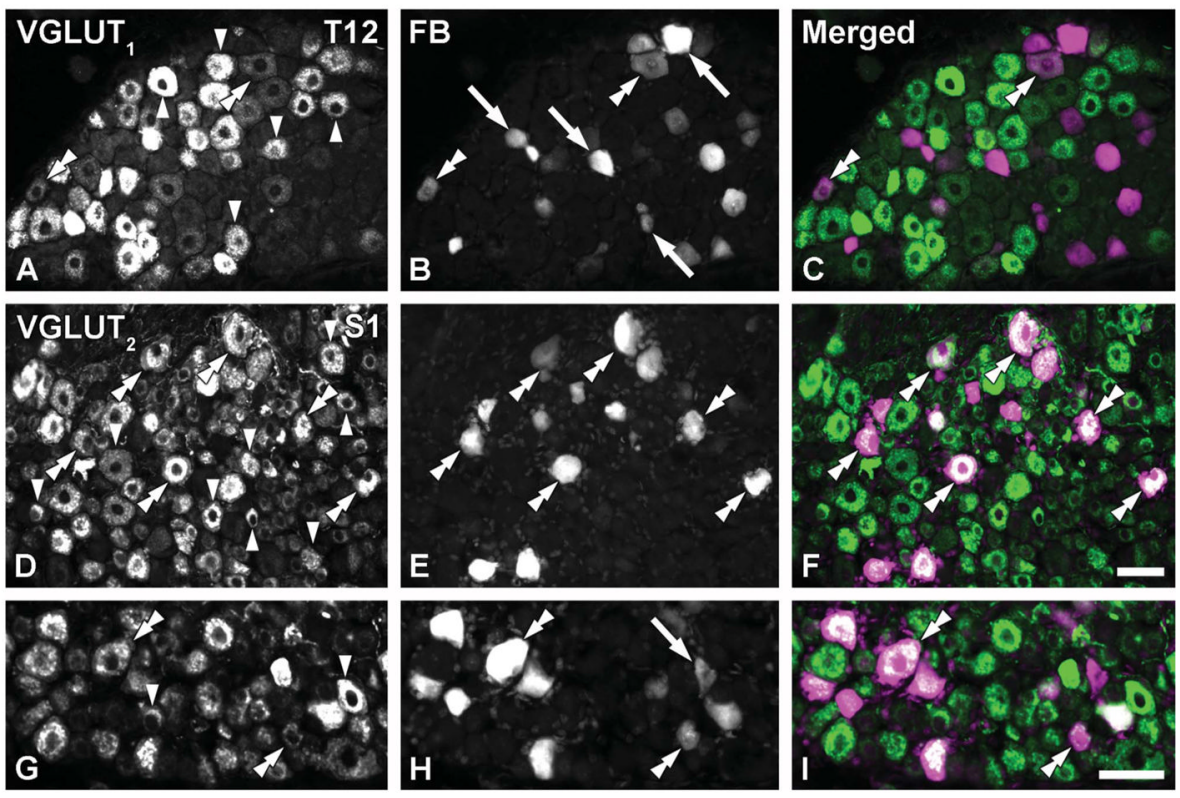

Figure 2.

Optical immunofluorescence photomicrographs of sections of T12 (A-C), or S1 (D-I) DRGs incubated with antiserum to $\operatorname{VGLUT}_{1}(\mathrm{~A})$ or $\operatorname{VGLUT}_{2}(\mathrm{D}, \mathrm{G})$. Retrogradely labeled colorectal DRG neurons containing FB $(\mathrm{B}, \mathrm{E}, \mathrm{H})$ are shown in red in the merged

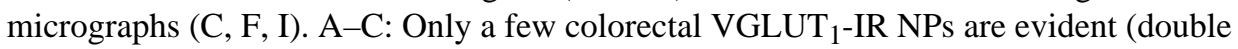

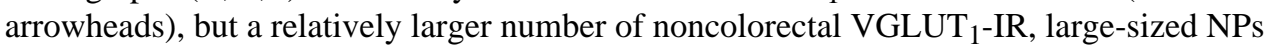
are present in the section (arrowheads in A) as are colorectal DRG NPs lacking the transporter (arrows in B). D-I: Abundant noncolorectal VGLUT 2 -IR NPs are present in S1 DRGs, spanning various neuronal sizes (arrowheads in D, G). Virtually all colorectal NPs exhibit VGLUT 2 -LI (double arrowheads); occasional colorectal NPs apparently lack this transporter (arrow in H). Scale bars $=50 \mu \mathrm{m}$ in $\mathrm{F}$ (applies to A-E); I (applies to $\mathrm{G}, \mathrm{H}$ ). [Color figure can be viewed in the online issue, which is available at wileyonlinelibrary.com.] 


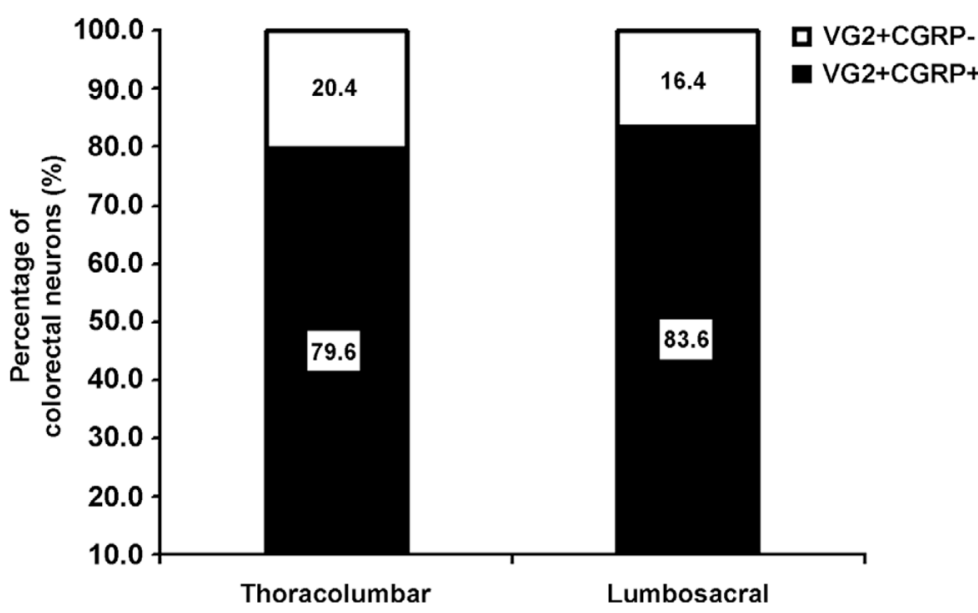

Figure 3.

Proportions of VGLUT $_{2}$-IR colorectal NPs lacking (unfilled segments) or coexpressing (filled segments) CGRP in thoracolumbar and lumbosacral DRGs. 

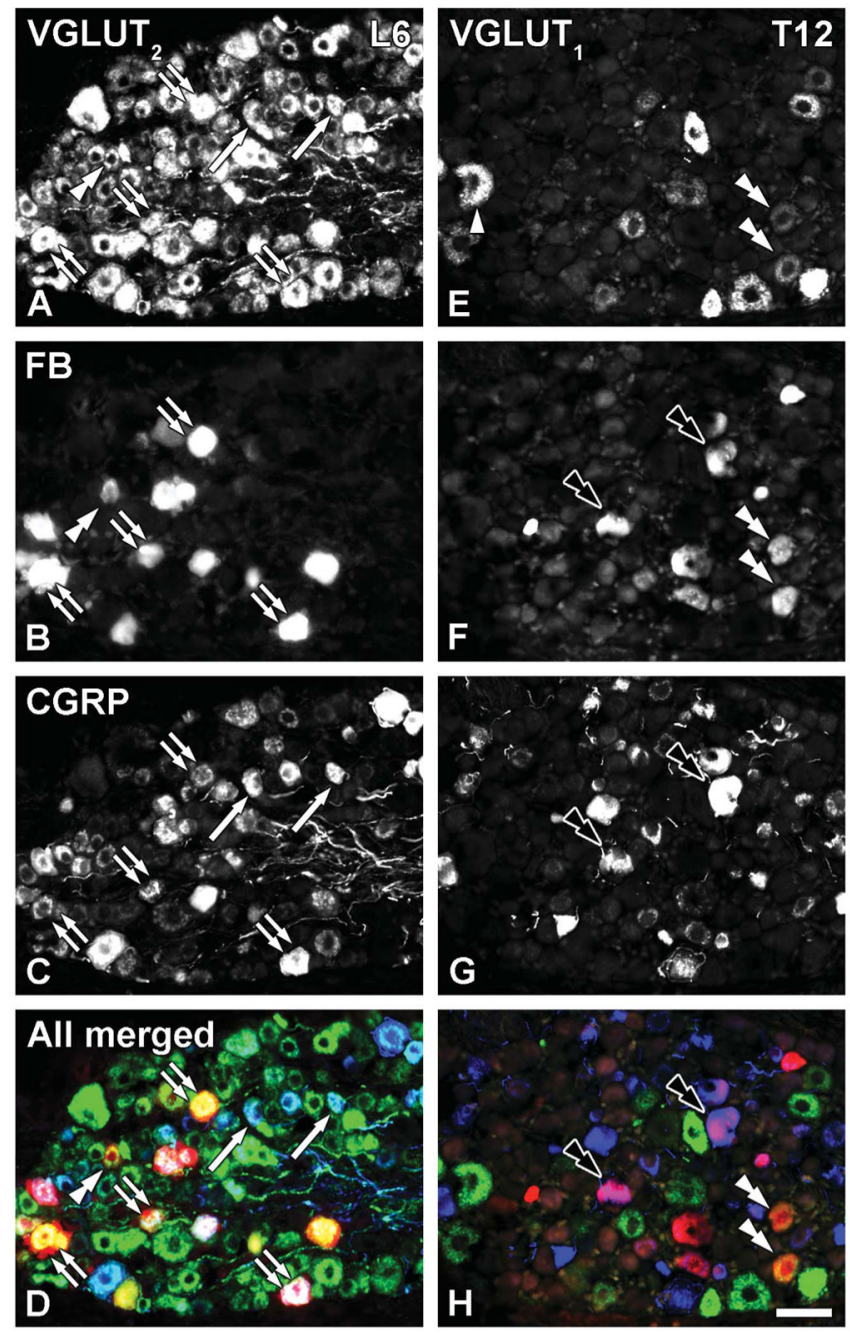

Figure 4.

Optical immunofluorescence photomicrographs of sections of L6 (A-D) or T12 (E-H) DRGs after coincubation with $\operatorname{VGLUT}_{2}(\mathrm{~A})$ or $\operatorname{VGLUT}_{1}(\mathrm{E})$ antiserum and CGRP antiserum $(C, G)$. Retrogradely labeled colorectal neurons containing FB (B, F) are shown in red in the merged micrographs $(\mathrm{D}, \mathrm{H})$. A-D: Virtually all VGLUT $_{2}$-IR colorectal NPs coexpress CGRP (double arrows). Occasional VGLUT 2 -only colorectal NPs are also evident (white double arrowheads). Additional VGLUT 2 /CGRP-IR noncolorectal NPs are present (arrows). E-H: Few VGLUT 1 -IR colonic NPs are present, and these lack CGRP (white double arrowheads). However, most colorectal NPs show CGRP-LI (black double arrowheads). Scale bar $=50 \mu \mathrm{m}$. [Color figure can be viewed in the online issue, which is available at wileyonlinelibrary.com.] 

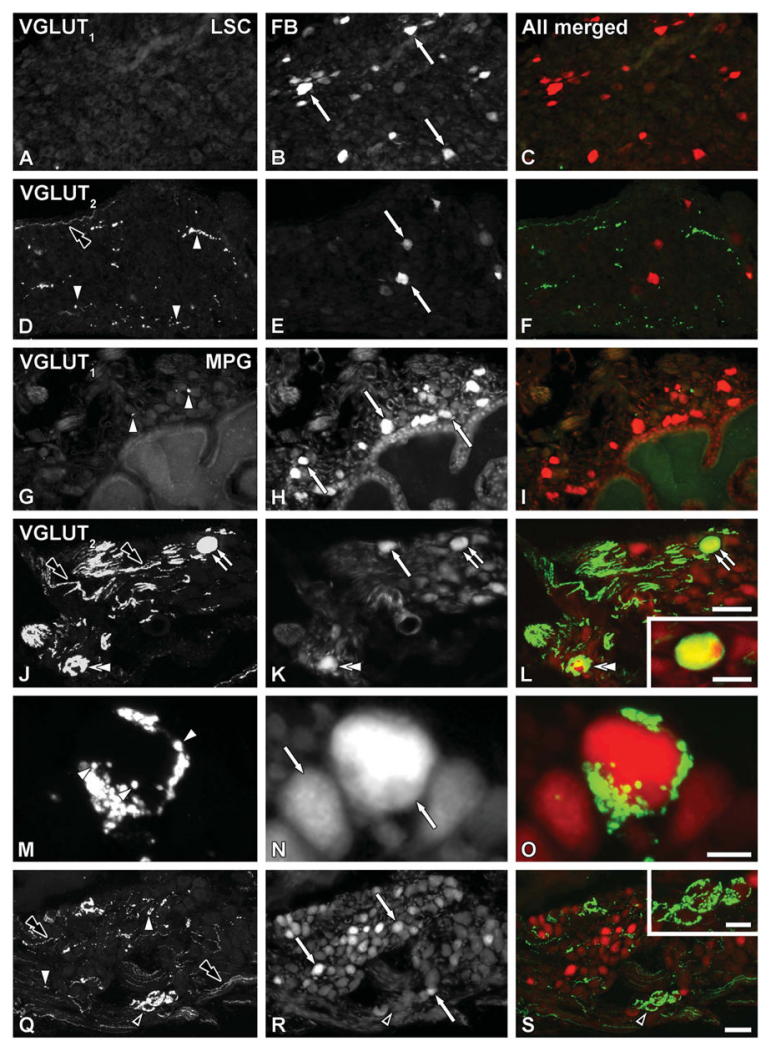

Figure 5.

Confocal (A, D, G, J, M, P) and optical (B, E, H, K, N, Q) immunofluorescence photomicrographs of sections of the LSC $(\mathrm{A}-\mathrm{F})$ or MPG $(\mathbf{G}-\mathbf{R})$ after incubation with $\operatorname{VGLUT}_{1}(\mathbf{A}, \mathbf{G})$ or $\mathrm{VGLUT}_{2}(\mathrm{D}, \mathrm{J}, \mathrm{M}, \mathrm{P})$ antiserum. Retrogradely labeled colorectal neurons containing FB (B, E, H, K, N, Q) are shown in red in the merged micrographs $(\mathbf{C}$, F, I, L, O, R). A-F: A number of colorectal NPs are detected in the LSC (arrows in B, E). Incubation with the VGLUT $_{1}$ antiserum failed to reveal any immunostaining, either in neurons or any other ganglionic structure $(\mathrm{A}, \mathrm{C})$. In contrast, VGLUT $_{2}$-LI is detected in fibers (black double arrowhead in D) and what appear to be varicosities (arrowheads in D) in the vicinity of colorectal LSC NPs. However, the latter were always VGLUT $_{2}$-negative (arrows in E). G-I: Only rare VGLUT 1 -IR puncta are found in the MPG (arrowheads in G). Note many FB labeled neurons (arrows in H). J-L: In contrast, presence of $\mathrm{VGLUT}_{2}$ in fibers (black double arrowheads), perineuronal baskets (white double arrowheads) (arrows in N), and rare colorectal NPs (double arrows; also shown at higher magnification in the inset in L) was detected in the MPG. M-O: A colonic MPG neuron is contacted by a VGLUT $_{2}$-IR perineuronal basket, where puncta are easily seen (arrowheads in M). P-R: In addition to a number of fibers (black double arrowheads in $\mathrm{P}$ ) and puncta (arrowheads in $\mathrm{P}$ ) seen in the MPG, note the presence of perineuronal VGLUT 2 -IR baskets around noncolorectal (black arrowheads in P-R) MPG NPs (shown at higher magnification in the inset in $\mathrm{R}$ ). Scale bars $=50 \mu \mathrm{m}$ in L (applies to A-K), R (applies to P, Q); $20 \mu \mathrm{m}$ in insets (L, R); $10 \mu \mathrm{m}$ in $\mathrm{O}$ (applies to $\mathrm{M}, \mathrm{N}$ ). [Color figure can be viewed in the online issue, which is available at wileyonlinelibrary.com.] 

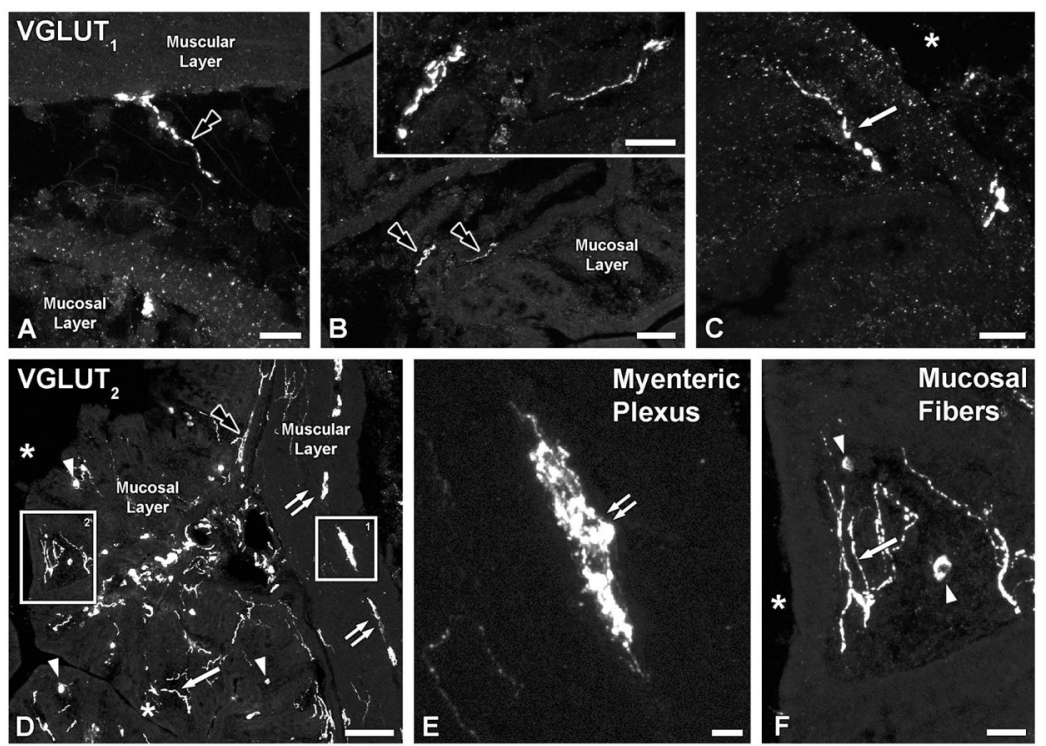

\section{Figure 6.}

Confocal immunofluorescence photomicrographs of transverse sections of the colorectum after incubation with $\operatorname{VGLUT}_{1}(\mathbf{A}-\mathbf{C})$ or $\operatorname{VGLUT}_{2}$ (D-F) antiserum (asterisks show the location of the colorectal lumen). A-C: Rare VGLUT 1 -IR fibers are shown in submucosal (black double arrowheads in A, B) and mucosal (arrow in C) layers in the colorectal wall (inset in B shows fibers at higher magnification). D-F: An abundant VGLUT 2 -IR neuropil is observed throughout the wall of the colorectum, including the myenteric plexus area (box 1; shown at higher magnification in E) as well as in the mucosa (box 2; shown at higher magnification in $\mathrm{F}$ ). Note the presence of $\mathrm{VGLUT}_{2}$ in fibers reaching very near the most luminal colorectal epithelium (arrows in D, F). VGLUT $_{2}$-IR fibers are also found in the submucosal layers (black double arrowhead in D), and create dense neuropil arrangements in the myenteric plexus (double arrows in D, E). Some sparsely located cells show fluorescence due to unspecific binding of the secondary antibody (white arrowheads in D, F). Scale bars $=100 \mu \mathrm{m}$ in D; $50 \mu \mathrm{m}$ in B; $20 \mu \mathrm{m}$ in $\mathrm{A}, \mathrm{C}$, E, inset in B; $10 \mu \mathrm{m}$ in F. 

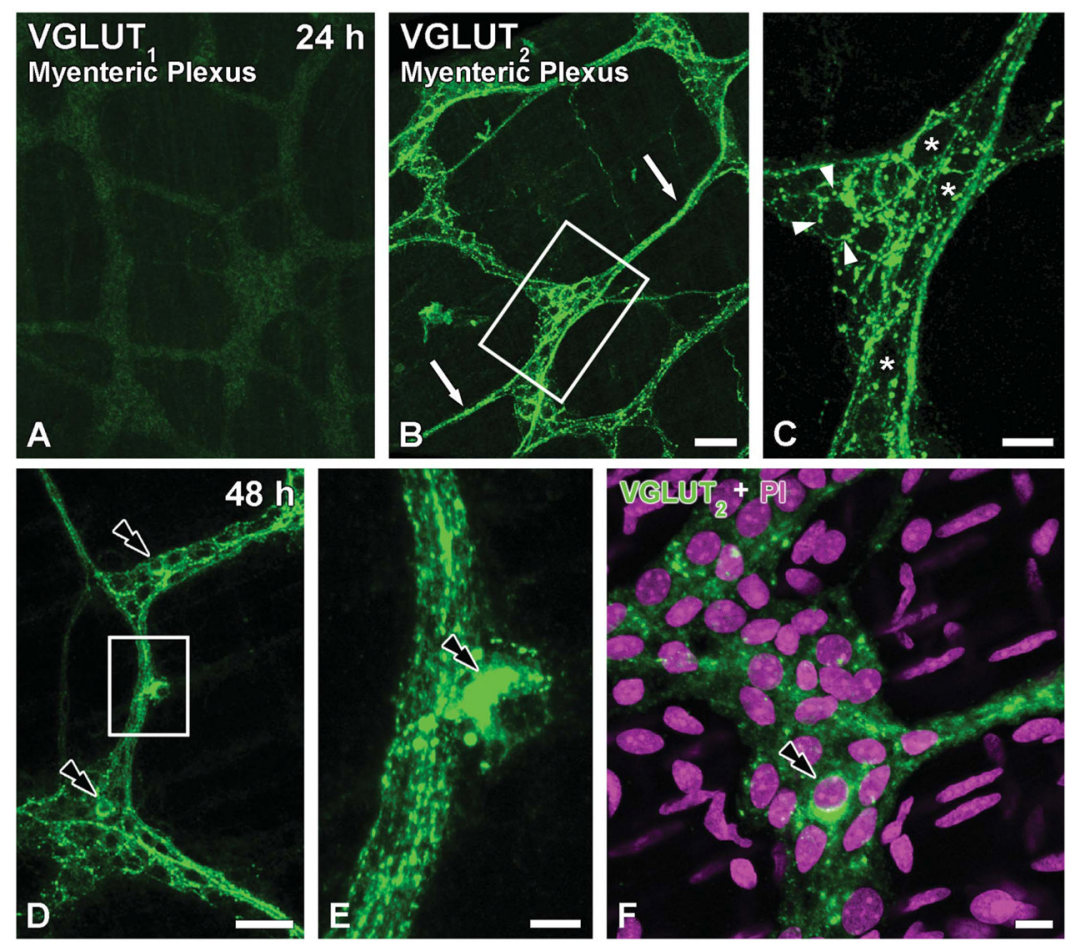

Figure 7.

Confocal immunofluorescence photomicrographs of whole-mount colorectal preparations after 24 hours (A-C) or 48h (D-F) free-floating incubation with VGLUT $_{1}$ (A) or VGLUT 2 (B-F) antisera (counterstained in F with propidium iodide, PI) (asterisks show the location of myenteric plexus NPs lacking VGLUT $_{2}$-positive neuronal cell bodies). A: VGLUT 1 -LI is absent in the myenteric plexus and surrounding longitudinal muscle. B, C: In contrast, an abundant $\mathrm{VGLUT}_{2}$-IR neuropil is observed in myenteric plexus ganglia, often connected by thick VGLUT 2 -IR nerve bundles (arrows in B). A high-power magnification of the box in $\mathrm{B}$ shows the delicate distribution of $\mathrm{VGLUT}_{2}$, adopting the appearance of varicose endings (arrowheads in $\mathrm{C}$ ) around $\mathrm{VGLUT}_{2}$-negative myenteric plexus neurons (asterisks). D-F: Forty-eight-hour incubation with the $\mathrm{VGLUT}_{2}$ antibody highlights the presence of a discrete number of myenteric plexus neurons expressing the transporter (black double arrowheads). PI staining confirms the association of this staining pattern with a cellular structure, in this case myenteric plexus neurons. Scale bars $=50 \mu \mathrm{m}$ in B (applies to A, D); $20 \mu \mathrm{m}$ in C; 10 $\mu \mathrm{m}$ in $\mathrm{E}, \mathrm{F}$. [Color figure can be viewed in the online issue, which is available at wileyonlinelibrary.com.] 

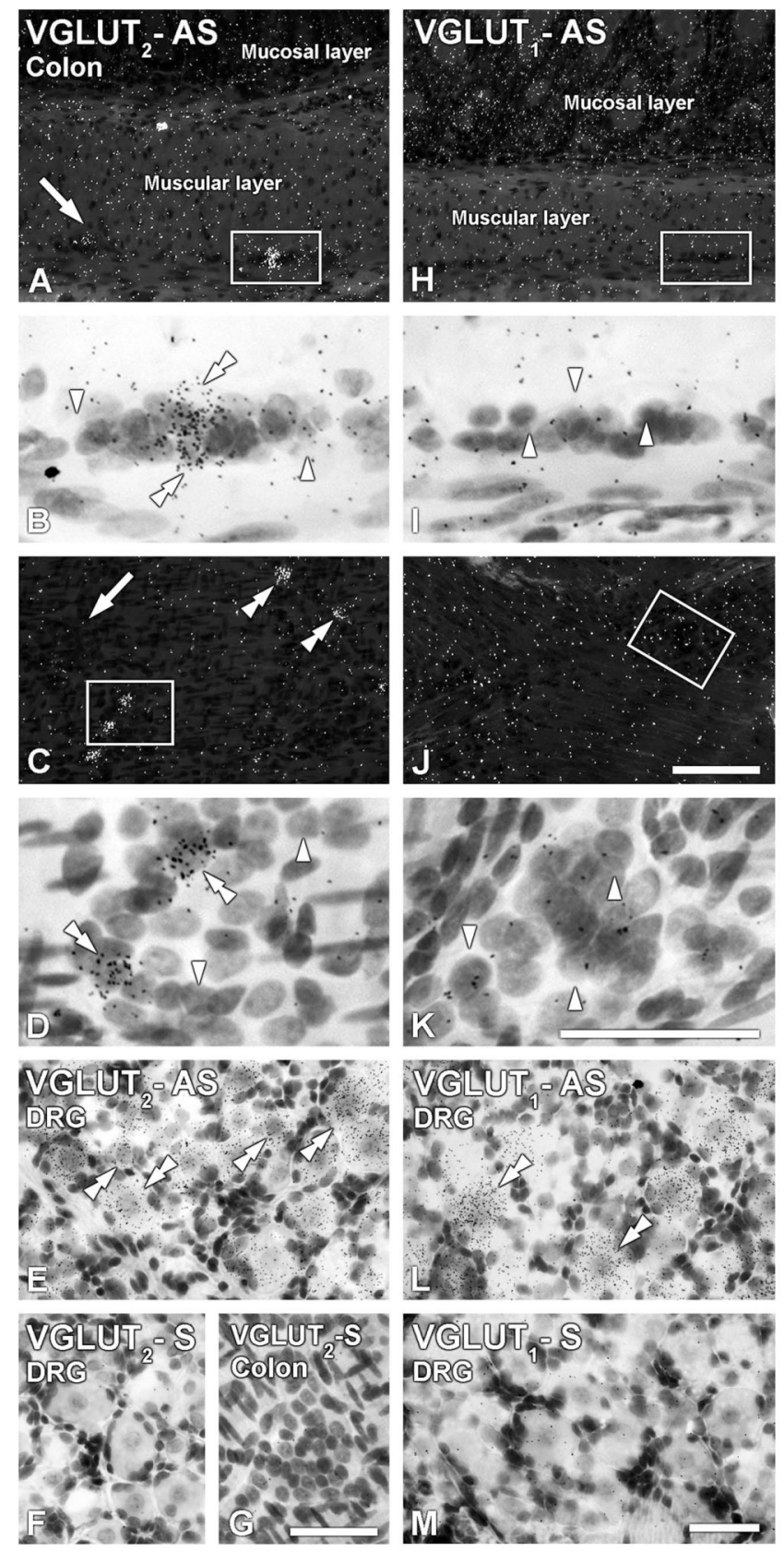

Figure 8.

Dark- (A, H, C, J) and brightfield (B, I, D, K, E, F, G, L, M) optical photomicrographs of colorectal (A-D, G; H-K) or DRG (E, F, L, M) sections, after hybridization with antisense (A-E; H-L) and sense (F, G, M) riboprobes against $\operatorname{VGLUT}_{2}(\mathrm{~A}-\mathrm{G})$ or $\operatorname{VGLUT}_{1}(\mathrm{H}-\mathrm{M})$ mRNAs. A-D: In transverse sections of the colorectum, VGLUT $_{2}$ binding is observed only at the level of the myenteric plexus, present in a discrete number of neurons, as seen in a magnified view of the box in A (double arrowheads in B). Myenteric plexus (arrows in A, C) as well as individual neurons (arrowheads in B) lacking $\mathrm{VGLUT}_{2}$ are also apparent. Tangential sections of the myenteric plexus confirm the presence of VGLUT 2 in some neurons throughout the plexus (double arrowheads in C, D). Many of the neurons present in each myenteric ganglia lack VGLUT 2 (arrowheads in D). E-G: The $\mathrm{VGLUT}_{2}$ antisense 
riboprobe is effective in showing DRG neuronal expression (double arrowheads in E). In contrast, incubation of the sections with sense riboprobe revealed no $\mathrm{VGLUT}_{2}$ binding in DRG (F) or myenteric plexus (G) sections. H-M: $\operatorname{VGLUT}_{1}(\mathrm{H}-\mathrm{K})$ mRNA was virtually

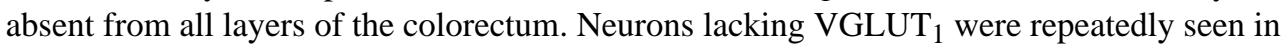
the myenteric plexus (arrowheads in I, K). Despite the lack of hybridization in the colon, the VGLUT $_{1}$ antisense riboprobe was efficient in labeling a number of NPs in DRGs (double arrowheads in $\mathrm{L}$ ). VGLUT $_{1}$ binding was absent in sections incubated with the sense riboprobe (M). Scale bars $=100 \mu \mathrm{m}$ in $\mathrm{J}$ (applies to A, H, C); $50 \mu \mathrm{m}$ in $\mathrm{K}$ (applies to B, I, D), in G, M (applies to E, L, F). 

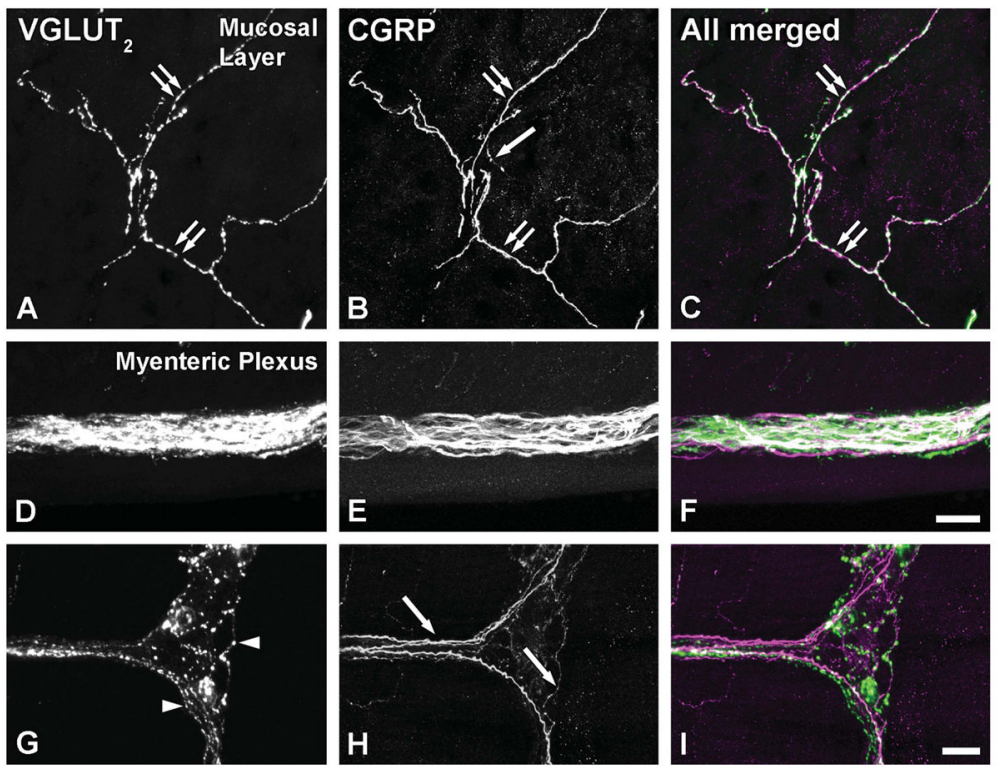

Figure 9.

Confocal immunofluorescence photomicrographs of parasagittal (A-C; G, H) and transverse (D-F) sections of the colorectum after coincubation with $\operatorname{VGLUT}_{2}(\mathrm{~A}, \mathrm{D}, \mathrm{G})$ and CGRP (B, E, H) antisera (merged figures are shown in C, F, I). A-C: Virtually complete colocalization between VGLUT 2 and CGRP is observed in the mucosal layers of the colorectum (double arrows). Additional CGRP-only fibers are also present (arrow in B). DF: In the myenteric plexus, a dense VGLUT $_{2}$ and CGRP-IR neuropil is detected. G-I: However, more detailed examination of the populations of VGLUT 2 -IR (arrowheads in G) and CGRP-IR (arrows in $\mathrm{H}$ ) fibers shows that they are virtually never overlapping. Scale bars $=20 \mu \mathrm{m}$ in I (applies to A-C, G, H); in F (applies to D, E). [Color figure can be viewed in the online issue, which is available at wileyonlinelibrary.com.] 
TABLE 1

Primary Antibodies Used

\begin{tabular}{|c|c|c|c|}
\hline Antigen & Immunogen & $\begin{array}{l}\text { Manufacturer; species antibody was } \\
\text { raised in, mono- vs. polyclonal; catalog } \\
\text { or lot number }\end{array}$ & Dilution used \\
\hline $\begin{array}{l}\text { Vesicular glutamate } \\
\text { transporter } 1 \\
\left(\text { VGLUT }_{1}\right)\end{array}$ & $\begin{array}{l}\text { rat } \mathrm{VGLUT}_{1} ; \text { C-terminal } 531-560 \\
\text { amino acid residues; raised in rabbit }\end{array}$ & $\begin{array}{l}\text { Frontier Science (Hokkaido, Japan); rabbit } \\
\text { polyclonal; \#VGluT1-Rb-Af500 }\end{array}$ & $1: 3,000-1: 4,000$ \\
\hline $\begin{array}{l}\text { Vesicular glutamate } \\
\text { transporter } 2 \\
\left(\mathrm{VGLUT}_{2}\right)\end{array}$ & $\begin{array}{l}\text { rat } \mathrm{VGLUT}_{2} ; \mathrm{C} \text {-terminal } 519-582 \\
\text { amino acid residues; raised in guinea } \\
\text { pig }\end{array}$ & $\begin{array}{l}\text { Frontier Science (Hokkaido, Japan); guinea } \\
\text { pig polyclonal; \#VGluT2-GP-Af670-1 }\end{array}$ & $1: 6,000-1: 8,000$ \\
\hline $\begin{array}{l}\text { Calcitonin gene } \\
\text { related peptide } \\
(\mathrm{CGRP})\end{array}$ & $\begin{array}{l}\text { rat CGRP conjugated to keyhole } \\
\text { limpet hemocyanin; raised in rabbit }\end{array}$ & $\begin{array}{l}\text { Sigma (St. Louis, MO); rabbit polyclonal; } \\
\text { \#C8198 }\end{array}$ & $1: 8,000(\mathrm{IF}) / 1: 40,000(\mathrm{TSA})$ \\
\hline
\end{tabular}

IF, indirect fluorescence; TSA, tyramide signal amplification. 
TABLE 2

Quantification of the Percentage of Colorectal NPs Expressing VGLUT 1 or VGLUT 2 in Thoracolumbar and Lumbosacral DRGs

\begin{tabular}{lcc}
\hline & VGLUT $_{1}$ & VGLUT $_{\mathbf{2}}$ \\
\hline Thoracolumbar & $15 \pm 1.8 \%$ & $98 \pm 1.2 \%$ \\
Lumbosacral & $8 \pm 1.1 \%{ }^{*}$ & $97 \pm 1.4 \%$ \\
\hline
\end{tabular}

${ }^{*} P \leq 0.05$ when comparing thoracolumbar vs. lumbosacral. 